Quaestio facti. Revista Internacional sobre Razonamiento Probatorio

Quaestio facti. International Journal on Evidential Legal Reasoning

Vol. 1 | 2020 pp. 31-66

Madrid, 2020

DOI: 10.33115/udg_bib/qf.i0.22327

Marcial Pons Ediciones Jurídicas y Sociales

(C) Pablo Rovatti

ISSN: 2604-6202

Recibido: 19/05/2019 | Aceptado: 18/09/2019

\title{
TESTIGOS NO DISPONIBLES Y CONFRONTACIÓN: FUNDAMENTOS EPISTÉMICOS Y NO EPISTÉMICOS*
}

\author{
Pablo Rovatti \\ Universidad de Buenos Aires \\ pablorovatti@hotmail.com
}

RESUMEN: El autor critica una tesis extendida en materia de derecho de confrontación, según la cual la falta de una oportunidad de interrogar a un testigo de cargo no disponible para el juicio vedaría la admisión de la declaración previa. Se analiza primero esa tesis desde una perspectiva instrumental-epistémica de la confrontación. Pero el aporte más significativo es el análisis de aquellas propuestas teóricas que defienden una regla rígida de inadmisión con base en razones no epistemológicamente dependientes. Por un lado, se examina si tiene sentido la idea de derechos procesales de intervención del acusado valiosos en sí mismos, no-instrumentales. Por el otro, se evalúa la capacidad de rendimiento de algunas de las posiciones más relevantes en esa línea, para concluir en que no alcanzan para justificar la tesis criticada.

PALABRAS CLAVE: derecho de confrontación; testigos no disponibles; sole or decisive rule; racionalidad epistemológica; derechos de intervención intrínsecamente valiosos.

\section{UNAVAILABLE WITNESSES AND CONFRONTATION: EPISTEMIC AND NON-EPISTEMIC FOUNDATIONS}

\begin{abstract}
The author criticizes an extended thesis on the right of confrontation, according to which the lack of an opportunity to cross-examine a prosecution witness unavailable for trial would pre-

*Agradezco especialmente las críticas y sugerencias del profesor Arturo Bárcena Zubieta a los sucesivos borradores de este artículo. Asimismo, agradezco las observaciones y comentarios de los profesores Edgar Aguilera García y Jordi Ferrer Beltrán, que integraron con el profesor Bárcena Zubieta el jurado que evaluó una versión preliminar de este texto presentada como trabajo de culminación del Máster en Razonamiento Probatorio de la Universidad de Girona. El agradecimiento se extiende a dos dictaminadores/as anónimos/as y a mis colegas de la Universidad de Buenos Aires Alan Limardo, Pablo Larsen, Juan Lucas Finkelstein Nappi, Damián Radiminski y Agustín Varela, por sus atentas lecturas y comentarios críticos.
\end{abstract}


clude the admission of the prior statement. Epistemic arguments are analyzed in the first place, but the paper's central contribution deals with non-epistemic reasons underlying confrontation right. In this context, the paper advances reasons for being skeptical about free-standing evidencial rights. Then, it develops an analysis about the ways in which confrontation has been theorized from a non-epistemic perspective. The author concludes that these theoretical proposals are not sufficiently compelling to support a strong confrontation right.

KEYWORDS: Right to test witness evidence; unavailable witnesses; sole or decisive rule; epistemic rationality; free-standing evidencial rights.

SUMARIO: 1 . Introducción.- 2. Para alcanzar la verdad: la confrontación como garantía de confiabilidad.- 3. Cuando la verdad no alcanza: ‘argumentos no-instrumentales como clave de interpretación? 3.1. Presentación: dos preguntas para encarrilar el análisis. 3.2. La primera pregunta: pensar en un mundo de decisores infalibles. 3.3. La segunda pregunta: qué tipo de fundamentos y a dónde nos llevan (si es que nos llevan a algún lado)._4. Palabras de cierre.

\section{INTRODUCCIÓN}

1.1. Hay consenso acerca de que la facultad de interrogar o hacer interrogar a los testigos de cargo es una garantía procesal que integra la noción de debido proceso ${ }^{1}$. Este derecho es parte integrante de los derechos procesales de intervención, que incluyen facultades de control de la evidencia, durante su práctica y con posterioridad, y se complementa con otras manifestaciones del derecho a la prueba, como las de proponer pruebas de refutación o pruebas de segundo orden, aportar todas las pruebas relevantes de las que se dispone y obtener una decisión racionalmente motivada sobre la quaestio facti (Ferrer Beltrán, 2007:54-9, 87-90; TARUfFo, 1992:56-8).

El ejercicio de ese derecho tiene lugar, en principio, en el juicio o vista pública. Más allá de las peculiaridades de cada arreglo institucional, por una cuestión de simple necesidad, al juicio precede una fase de investigación o indagación, que servirá de base a la acusación. Al menos en el caso de los delitos de acción pública o perseguibles de oficio, la policía, y luego la fiscalía o el juzgado de instrucción, según el sistema de que se trate, entre otras actividades encaminadas a la averiguación de

1 Así está reconocido, con fórmulas ligeramente distintas en los artículos 6(3)(d) del Convenio Europeo para la Protección de los Derechos Humanos y de las Libertades Fundamentales (en vigor desde 1953), 14(3)(e) del Pacto Internacional de Derechos Civiles y Políticos (1976) y 8(2)(f) de la Convención Americana sobre Derechos Humanos (1978). La fórmula de la Sexta Enmienda de Constitución de los Estados Unidos de América (1791) es la siguiente: «in all criminal prosecutions, the accused shall enjoy the right [...] to be confronted with the witnesses against him». Suele citarse como antecedente remoto el diálogo entre Festo y el rey Agripa sobre el trato debido al prisionero Pablo. Los sumos sacerdotes y ancianos judíos presentaban contra Pablo graves e insistentes acusaciones, y le pedían a Festo lo hiciese trasladar de Cesarea a Jerusalén, mientras preparaban una celada para matarlo en el camino. Más tarde, Festo expone al rey el caso, y recuerda: «A estos respondí que no es costumbre de los romanos entregar un hombre a la muerte antes de que tenga delante de sí a sus acusadores, y pueda defenderse de la acusación presentada en su contra» (Hechos de los Apóstoles, 25:16). 
la verdad, reciben declaraciones a los testigos del hecho posiblemente criminal o de otros hechos vinculados. De esta actividad, más o menos formalizada, se deja algún tipo de registro: puede consignarse en un acta, grabarse en cinta de audio o filmarse y obtener un registro de audio y vídeo.

El caso es que incluso en las investigaciones más diligentes (y, por incontables factores, la mayoría no lo son tanto como desearíamos) el tiempo pasa entre la noticia de un hecho posiblemente delictivo y su enjuiciamiento. Sucede, en ciertas ocasiones, que un testigo declara ante la policía o ante la autoridad a cargo de la investigación, pero muere antes del juicio, o no está en condiciones psíquicas para declarar, o no es posible encontrarlo, o está demasiado atemorizado como para presentarse. A veces es posible prever alguno de estos factores e intentar remediarlo de antemano, otras veces no.

Sabedores de estas complicaciones, los códigos procesales de la tradición continental-europea y sus herederos latinoamericanos, del mismo modo que la regulación de la hearsay rule en el common law, contemplan, por lo general, una cláusula o set de cláusulas que especifican en qué casos y bajo qué condiciones cabría admitir la lectura o exhibición del registro de la declaración anterior cuando una testigo, por alguna razón atendible, no está disponible.

Aquí no acaba la cosa. Como el derecho de examinar, interrogar o confrontar a los testigos es uno de orden constitucional —una garantía procesal mínima, según los instrumentos de derechos humanos - una posición bastante extendida en la jurisprudencia y la doctrina sostiene vehementemente que la falta de una oportunidad de interrogar a la testigo de cargo no disponible veda la introducción por lectura o exhibición de la declaración previa. Tanto da que la testigo haya muerto repentina e inesperadamente, que los profesionales de la salud indiquen que su estado psíquico le impide volver a declarar o que se hayan hecho todos los esfuerzos razonablemente posibles para dar con una testigo que ha desaparecido. Si no hubo alguna oportunidad previa de confrontación, se dice, la declaración, por más confiable que parezca, no ingresa ${ }^{2}$. Otros han relativizado un poco esta afirmación, y se han preguntado además por el peso relativo de esa declaración en la fundamentación de la condena.

\footnotetext{
2 A grandes rasgos, esa es la interpretación que ha hecho de la Confrontation Clause la Corte norteamericana, para el caso de testimonial hearsay, a partir de Crawford v. Washington, 541 U.S. 36 (2004). Otras altas cortes de justicia han seguido esa línea. Sirva como ejemplo - que debo al Prof. Arturo Bárcena Zubieta- el caso de la Sala Primera de la Suprema Corte mexicana (Amparo directo en revisión 243/2017, Acuerdo de 10 de enero de 2018) que declaró inconstitucional el art. 374, fracción II, inciso d), del Código de Procedimientos Penales para el Estado de México, «en la parte que prevé la incorporación a la audiencia oral, mediante lectura, de la declaraciones de testigos que consten en diligencias anteriores, cuando se ignore su residencia actual y, por ello, no haya sido posible solicitar su desahogo anticipado», con base en que vulnera los principios de contradicción e inmediación. Pareciera, no obstante, que esa misma Sala Primera dio marcha atrás en una sentencia dictada meses después (Amparo directo en revisión 2929/2018, Acuerdo de 28 de noviembre de 2018), en la que se analizó la constitucionalidad del art. 376 fracción IV de la Ley del Proceso Penal para el Estado de Guanajuato, muy similar al citado artículo del CPP para el Estado de México. En ese fallo se reproduce de modo algo confuso la sole or decisive rule europea.
} 
Si la declaración es la prueba única o si ha sido decisiva, habría una infracción al derecho en cuestión, en otro caso no ${ }^{3}$.

Pocos temas han despertado tanto debate ${ }^{4}$ y es comprensible que así sea. Es mucho lo que está en juego en las discusiones sobre confrontación: si el caso de la fiscalía depende de la declaración de la testigo no disponible, la acusación fracasará, incluso cuando sea evidente que la admisión de ese elemento de prueba, en conjunto con otros, habría conducido a demostrar más allá de toda duda razonable ${ }^{5}$ la culpabilidad del acusado.

En este trabajo intento explicar por qué esas interpretaciones del derecho de confrontación son insostenibles. Para ello, empiezo por la mirada dominante, que llamo instrumental-epistémica, para la cual el fundamento de la garantía está en dar a la defensa una herramienta que le permita testear la calidad de la información que introduce la testigo de cargo y, con ello, asegurar la confiabilidad de la evidencia.

3 Puede rastrearse la historia de la sole or decisive rule europea a partir de: TEDH, Doorson v. Países Bajos, no. 20524/92, 26-mar-1996, esp. \$76; Lucà v. Italia, no. 33354/96, 27-feb-2001, esp. \$40-45, Al-Khawaja y Tahery v. Reino Unido, nos. 26766/05 y 22228/06, 20-ene-2009, esp. \$36-37. Para un análisis crítico y riguroso de la vasta jurisprudencia de la Corte Europea hasta el primer Al-Khawaja (2009), consúltese [2009] UKSC 14, \$63-105 y Anexos 2 y 3 a la sentencia. Antes había emprendido esa misma tarea la División Penal de la Corte de Apelaciones británica: [2009] EWCA Crim 964, \$3058.

4 Sirva como prueba el hecho de que, en un período de apenas quince ańos: (i) la Corte norteamericana modificó sustancialmente su comprensión de la Confrontation Clause, abandonando la línea de Ohio v. Roberts, 448 U.S. 56 (1980) e iniciando una nueva con Crawford; a este leading case le siguieron un buen número de precedentes que intentaron arrojar luz sobre la distinción testimoniallnontestimonial y otros aspectos sobre hearsay y confrontación: Davis v. Washington, 547 U.S. 813 (2006); Giles v. California, 554 U.S. 353 (2008); Melendez-Diaz v. Massachusetts, 557 U.S. 305 (2009); Michigan v. Bryant, 562 U.S. 344 (2011); Bullcoming v. New Mexico, 564 U.S. 647 (2011); Ohio v. Clark, 576 U.S. _ (2015); (ii) la División Penal de la Corte de Apelaciones y la Suprema Corte del Reino Unido, después de que ese Estado fuera condenado por la Corte Europea en el primer Al-Khawaja, dictaron dos pronunciamientos históricos en $R$. $v$ Horncastle, donde explican y defienden la regulación de la hearsay rule en la Criminal Justice Act (CJA) 2003, revisan la jurisprudencia europea sobre el art. 6(3)(d) del Convenio y le sugieren al Tribunal de Estrasburgo nada menos que mejoras en la manera de interpretarlo; (iii) la Corte Europea, que venía perfilando a la sole or decisive rule como una regla aparentemente absoluta e inflexible [y abandonaba así una línea más tópica que incluía precedentes como $A s c h$ v. Austria (no. 12398/86, 26-abr-1991) y Artner v. Austria (no. 13161/87, 25-jun-1992)], reconsideró la cuestión en Al-Khawaja y Tahery v. Reino Unido (nos. 26766/05 y 22228/06, 15-dic-2011) y luego en Schatschaschwili v. Alemania (no. 9154/10, 15-dic-2015), dos decisiones fundacionales de la Gran Sala. Estas discusiones, como podía esperarse, repercutieron en otros muchos lugares del mundo. Además del caso mexicano, ya recordado, puede ponerse como ejemplo el argentino. La Corte Suprema de este país, cuya posición no es del todo clara y ha dado lugar a muchos debates, se pronunció en dos precedentes importantes: Benitez (2006) y Gallo López (2011), publicados en Fallos: 329:5556 y 334:725, respectivamente. La lista, desde luego, podría extenderse, pero un relevamiento exhaustivo de la jurisprudencia de esos y otros tribunales no está entre los objetivos de este trabajo. Por otro lado, ofrecer una referencia completa de los académicos que se han ocupado del asunto es una tarea impracticable.

5 Uso, solo por comodidad, este estándar de prueba, sin entrar en la enorme discusión sobre sus virtudes y defectos, ni en el debate anexo acerca de si un estándar tal viene impuesto por la presunción de inocencia. 
Aclaro que no voy a detenerme demasiado aquí por dos razones. Por un lado, si la confiabilidad es el norte de la confrontación, bastan algunos ejemplos significativos para demostrar que la regla de inadmisión es exageradamente sobreinclusiva. Lo ha demostrado ya la Corte británica en Horncastle $e^{6}$ y, justamente a raíz de un diálogo fructífero con esta, la propia Corte Europea, aunque con alguna reserva, a partir de Al-Khawaja ${ }^{7}$. En lo que respecta a la academia, por otro lado, buena parte de los sostenedores de la tesis que aquí cuestiono admiten su derrota en la arena de los argumentos sobre la racionalidad epistemológica de la regla, pero — como veremosañaden a renglón seguido que la confiabilidad no es el (único) objetivo o raison d'être de la confrontación.

Precisamente por esto, el aporte que considero más significativo consistirá en poner a prueba otras propuestas, en general teóricas más que jurisprudenciales, sobre los fundamentos del derecho y sobre sus alcances. Se trata de perspectivas que defienden la solución que critico, pero no lo hacen (o no lo hacen solamente) a través de una apelación a la racionalidad epistemológica de la regla. En cambio, apoyan la defensa de una regla-Crawford o de otra similar como la sole or decisive rule europea, en razones no-epistemológicamente-dependientes.

El análisis de tales propuestas se divide en tres apartados. En el primero, expongo algunas de ellas y presento los dos interrogantes que sirven para encarrilar la argumentación posterior. En el segundo, me ocupo de la pregunta acerca de si tiene realmente sentido la idea de derechos procesales de intervención del acusado valiosos en si mismos, esto es, no-instrumentales a la evitación del riesgo de injusticia sustantiva. En el tercero, suspendo el juicio sobre esa pregunta más general, analizo algunas de las más frecuentes argumentaciones sobre los valores subyacentes a la confrontación y explico por qué, contrariamente a lo que afirman, no alcanzan para justificar la interpretación criticada en casos de testigos no disponibles.

Finalmente, formulo una serie de conclusiones a partir de los argumentos expuestos. La misión de este texto estará cumplida si logra, sino destruir, al menos hacer tambalear la estructura argumentativa donde buscan refugio los defensores de la tesis que critico. Por razones de extensión, deberé dejar para otra oportunidad, en cambio, la presentación acabada de una propuesta propia de interpretación del derecho de confrontación, que permita resolver razonablemente los casos de testigos ausentes o no disponibles y que tenga en consideración el mecanismo procesal conocido como anticipo de prueba, que muchas legislaciones prevén.

1.2. Algunas aclaraciones preliminares. En primer lugar, como se habrá advertido ya, en el trabajo me refiero a ciertos precedentes de la Corte Europea, de la Suprema Corte británica y de la Suprema Corte norteamericana. Las mismas razones de ex-

6 [2009] UKSC 14, \$91. Véase, asimismo: [2009] EWCA Crim 964, \$61-64.

7 TEDH (GS), Al-Khawaja y Tahery, \$129-147. Un análisis muy agudo del diálogo entre la Corte Europea y la británica es el de RedmaYne (2012). 
tensión me impiden presentar, siquiera resumidamente, la evolución y aspectos más salientes de esa jurisprudencia, lo que me obliga a asumir que son conocidos ${ }^{8}$.

En segundo lugar, en el texto utilizo indistintamente las expresiones derecho de "confrontación", derecho a "examinar» a los testigos "de cargo", de «interrogarlos» o de «contrainterrogarlos». No es que el texto de las cláusulas me parezca irrelevante o que, a todo evento, las expresiones sean intercambiables. Desde luego no lo es, y hay buenos análisis que lo explican cuando es necesario. La Constitución norteamericana, por caso, pone énfasis en el derecho a ser confrontado con los testigos de cargo y así se explica un énfasis marcado en la idea de enfrentamiento cara a cara, pero la redacción de la cláusula puede dar lugar también a pensar que la cross-examination, venerada en Crawford, no era aquello en lo que estaban pensando los Padres Fundadores, pues el derecho, como quedó redactado, es uno pasivo a ser confrontado, y no uno activo de confrontar (MADDEN, 2012:409-412).

Los instrumentos de derechos humanos no usan esa misma expresión - la de la «confrontación»- y esto sugiere que el enfrentamiento cara a cara del acusado con el testigo no tiene el mismo peso, aunque no quiere decir que no tenga ninguno (DíAz Cantón, 2009:233-243). Más importante aún, el de «interrogar» a los testigos no es, ni puede ser, necesariamente equivalente a una oportunidad de "contra-examinar» o "contra-interrogar», si usamos estos términos estrictamente, sencillamente porque hay variadas maneras de preguntar y no en todas las tradiciones jurídicas esto se hace mediante el instrumento o técnica adversarial de la cross-examination (JACKsON y Summers, 20I2:335; Schauer, 2009:211-214) 9 .

En esta misma línea, «hacer interrogar» no es idéntico a simplemente «interrogar», y la coexistencia de ambas fórmulas en los instrumentos de derechos humanos parece consciente de que no en todos los sistemas los abogados conducen los interrogatorios; en algunos lo hace el presidente del tribunal y, en todo caso, las partes formulan preguntas a través suyo o con su aprobación previa (Trechsel, 2005:311).

Por último, en el art. 8(2)(f) de la Convención Americana el derecho de interrogar está referido los testigos "presentes en el tribunal», lo que podría querer decir que el instrumento hizo explícita la posibilidad de que los testigos no pudieran estar presentes para la etapa del juicio, o interpretarse como un

8 El lector no del todo familiarizado con el tema encontrará buenos análisis y referencias en: TREChSel (2005:29I-326); Jackson y Summers (20 I 2:325-366); Miranda Estrampes (20 i 8:299-366); García (2002), SANCINETTI (2002:83 I-892); TOMKOVICZ (20 I I:325-400); MADDEN (20 I 2:397-409); Nanzer (2008:347-358); Dennis (2010); O’Brian (2005 y 20i i); Redmayne (20 io y 20I 2); Choo (20I3); DE WILDE (2013).

9 Más ampliamente sobre la cross-examination: TARUfFo (2009:I79-84) y Carofiglio (2007). 
sustituto neutro para la expresión "testigos de cargo» ${ }^{10}$, o simplemente como una limitación del ámbito de operatividad de la garantía a la etapa de juicio (en este último sentido, Trechsel, 2005:291).

En suma, el análisis del texto no es para nada despreciable, especialmente cuando se conocen los antecedentes y se documentaron las discusiones que condujeron a optar por uno en lugar de otro. Sin embargo, a los fines que aquí me propongo, esas sutilezas de la interpretación literal no son de mucha ayuda.

En tercer lugar, voy a referirme de modo general a testigos no disponibles o ausentes o a la indisponibilidad (unavailability) de un testigo, sin especificar en la mayor parte de los casos si esa ausencia en el juicio obedece a que la persona ha muerto, no se la encuentra, no está en condiciones de declarar u otras. El objetivo de este trabajo no es discutir cuando hay buenas razones o motivos atendibles para considerar que, efectivamente, un testigo no está disponible. En ciertos casos esto no genera dudas, como cuando ha muerto repentina e imprevisiblemente. En otros, habrá espacio para la discusión ${ }^{11}$. Mi análisis se ubica, salvo que haga explícito lo contrario, en un momento posterior al de esa pregunta inicial y presupone una respuesta afirmativa a tal interrogante.

Por último, el trabajo se limita a los casos de testigos ausentes. No analizo aquí los casos de testigos anónimos o de identidad reservada, aunque estos han dado lugar a una rica jurisprudencia enfocada también en el derecho a la confrontación.

\section{PARA ALCANZAR LA VERDAD: LA CONFRONTACIÓN COMO GARANTÍA DE CONFIABILIDAD}

2.1. Se considera por lo general que el principal, o uno de los principales ${ }^{12}$ objetivos del derecho de interrogar o hacer interrogar a los testigos de cargo es el de permitir al acusado controlar la confiabilidad de la información que estos introducen o sembrar dudas sobre su credibilidad. De este modo, la posibilidad de confrontación es un instrumento que se pone en manos de la persona expuesta a las consecuencias

${ }^{10}$ Lo que podría defenderse bajo esta lógica: la prueba admitida ante el tribunal es común, no pertenece a la parte que la ofreció (no se puede renunciar o desistir unilateralmente); además, no hay testigos en contra o a favor del acusado; a los testigos se les pide una identificación con la verdad y no con alguna de las partes. Sobre la idea contraria de "polarización de los medios de prueba» propia de un sistema adversarial, DAMAšKa $(1997: 85-7,104)$; sobre la idea de comunidad probatoria, MaIER (1989:876-7).

11 Cabe debatir, por ejemplo, si el Estado ha hecho todos los esfuerzos que cabía razonablemente exigir para dar con un testigo clave de paradero desconocido; o si basta un temor general, no fundado en acciones concretas del acusado o personas asociadas a él para que el testigo no concurra a declarar o, en cambio, deben tomarse medidas alternativas que comprometan en menor medida la posibilidad de confrontación; entre otras cuestiones de la misma índole que merecerían un tratamiento separado.

12 De los objetivos no instrumentales de la confrontación, que ciertas propuestas teóricas reconocen, me ocupo en el tercer apartado. 
de una decisión potencialmente equivocada, en la asunción de que su empleo puede contribuir a evitar el error de las personas que juzgan ${ }^{13}$.

En esto se piensa cuando se sostiene que se trata de un derecho que provee a la defensa de medios para testear la fiabilidad de la evidencia y, de este modo, promover la rectitud del veredicto, evitando posibles casos de injusticia sustantiva (DE WILDE, 2013:157; al menos parcialmente, TreCHSEL, 2005:292-3). La garantía emerge de la desconfianza hacia los interrogatorios tomados unilateralmente y por ello alienta la práctica contradictoria de la prueba, el examen y contra-examen, actividad a partir de la cual el acusado no sólo tiene una oportunidad de exponer la mentira y desafiar la memoria del testigo, sino también de forzarlo a declarar frente al jurado (o tribunal), de modo que sus miembros puedan observar su comportamiento durante el interrogatorio y juzgar así si es digno de confianza ${ }^{14}$.

El derecho de confrontación le provee al acusado la facultad de requerir que aquellos que brindan evidencia de cargo lo hagan en su presencia y en presencia del llamado a decidir (Friedman, 1998a:1011), que lo hagan bajo juramento de decir verdad y que se sometan al contra-interrogatorio de la defensa (Toмкоvicz, 2011:359-60). Un testigo que debe enfrentar la mirada del acusado y pronunciarse bajo juramento probablemente sea más cuidadoso, preciso y veraz, mientras que a través del contrainterrogatorio el acusado podrá poner de relieve donde están los agujeros en la historia, e invitar al testigo a complementar, aclarar o revisar esa historia, de modo que el decisor y el público puedan oír toda la verdad (AMAR, 1996:688-690).

Los análisis estándar de la hearsay rule, emparentada y al menos parcialmente superpuesta con el derecho de confrontación ${ }^{15}$, son claros a este respecto: juramento

13 Como este derecho, otros muchos sirven a los fines epistémicos del proceso. Además del derecho a confrontar a los testigos de cargo, LAUDAN (2006:298) ejemplifica con el derecho a contar con un abogado, a conocer la información exculpatoria en poder de la acusación, a saber en qué consisten los cargos, a presentar testigos y otras pruebas, a ser juzgado en audiencia pública, a impugnar la decisión.

14 Así explicado ya en Mattox v. United States, 156 U.S. 237, 242-3 (1895). Mattox es generalmente considerado el primer precedente significativo de la Corte norteamericana sobre la relación entre cláusula de confrontación y regla hearsay. Ante de ese precedente, la Corte se había pronunciado en Reynolds v. United States, 98 U.S. 145 (1878). Véase, con mayor detalle, Toмкоvicz, 2011:329-331.

15 En Crawford la Corte norteamericana enfatiza la diferencia a partir de una mirada histórica de la cláusula de confrontación, que conduce a la afirmación de que la garantía no resulta aplicable a los casos de non-testimonial hearsay, que quedan así librados a la regulación no constitucional de las Federal Rules of Evidence (FRE) o del derecho probatorio estadual. Es notable la influencia de FrIEDMAN (1998a y b) en Crawford, como señala Redmayne (2010:13). No se hace un distingo semejante, en cambio, en la jurisprudencia previa (Toмкоvicz, 2011:329-354). Tampoco la Corte británica diferencia en Horncastle entre subcategorías de hearsay según caigan o no bajo el alcance del art. 6(3)(d) del Convenio Europeo. De todos modos, hay algunas diferencias obvias entre confrontación y hearsay: la hearsay rule se aplica parejamente a la evidencia propuesta por la acusación y la defensa, mientras que el derecho de confrontación protege solo al acusado; la hearsay rule se aplica en general también en casos donde la persona que brinda una declaración hearsay está presente en el debate, mientras que esto difícilmente plantee un caso constitucional de confrontación; por último, como en Crawford, suele considerarse que el derecho de confrontación alcanza a los testimonios brindados o recibidos con el fin de ser empleados contra una persona en un proceso legal, mientras que la regla hearsay no se limita a esos casos (O'BRIAN, 
de decir verdad, posibilidad del juzgador de apreciar el comportamiento del testigo y cross-examination son los componentes de la tríada, cuya ausencia, en conjunto con otros factores de organización institucional ${ }^{16}$, explican esa regla prototípica del derecho probatorio del common law, incluso en las elaboraciones más sofisticadas sobre sus fundamentos o principios subyacentes (STEIN, 2005:189-196; Ho, 2008:231283).

En la tradición continental-europea, que no conoce de una hearsay rule ni -más generalmente- de reglas de exclusión intrínsecas (DAMAŠKa, 1997:30-3; Ferrer BeLtrán, 2007:44-5, 85-6), el asunto de la confrontación se entronca con la preferencia por la inmediación, oralidad y contradicción en la práctica de la prueba (NANZER, 2008:359-6I; GUARIGLIA, 2005:26-8; AlCÁCER GUIRAO, 2013:3, 13) ${ }^{17}$ que se interpretan, en conjunto, como un buen medio para la averiguación de la verdad, siempre que se lo use adecuadamente (ANDrÉs IBÁŃEZ, 2009:58-64).

FERrua (1992:248-54) señala que, aunque los procedimientos por los cuales se articula "el contradictorio» no pueden definirse a priori, hay dos aspectos centrales de la garantía. Por un lado, «el derecho de las partes de buscar, desde sus opuestas perspectivas, las fuentes de prueba», lo que requiere tanto de un acto informativo de la imputación en determinado momento de la investigación, como del reconocimiento del tiempo y los medios adecuados para ese fin. Por el otro, en lo que aquí interesa especialmente, «la intervención de las partes en la formación de las pruebas», que varía según el tipo de que se trate, pero que "adquiere su nivel más alto» en el testimonio, pues allí «la prueba se forma directamente por obra de las partes». En este punto, FERRUA destaca el valor del examen cruzado, que «antes de ser un derecho individual», "es una técnica de reconstrucción de los hechos», un instrumento útil para obtener «la máxima contribución probatoria de los testigos y de los imputados, corriendo el menor riesgo posible de declaraciones falsas», y cuyo presupuesto epistemológico «es que la verdad se puede manifestar, independientemente de la voluntad de las partes, precisamente en la conflictividad generada por las opuestas perspectivas, en el choque dialéctico y ritual entre los antagonistas durante la formación de la prueba oral» ${ }^{18}$.

20i i:93-94; Redmayne, 2010:3-6, donde destaca la importancia de la diferencia para apreciar en sus justos términos el valor de algunos de los argumentos y ejemplos de la Corte británica en Horncastle).

${ }^{16}$ DAMAŠKA, 1997:31-3, 41-115. Su lúcida explicación multifocal considera, entre otros factores, los siguientes: jueces legos, veredictos crípticos, tribunales de primera instancia divididos o bifurcados, procedimientos concentrados, preferencia histórica por fresh evidence, y varias derivaciones del sistema adversarial (polarización de los medios de prueba, impronta adversarial en la carga de aportar pruebas, la identificación de los testigos con las partes y las técnicas de coaching, etc.).

17 De modo más general: Ferrer Beltrán (2007:87-90) y Ubertis (2015:56-9).

18 El autor brinda las razones que apoyarían la «superioridad de esa técnica» sobre otros modos de interrogar, y esas razones también están en línea con la desconfianza hacia los interrogatorios unilaterales y la necesidad evitar posibles casos de injusticia sustantiva. En primer lugar, el acto de interrogar «nunca es plenamente neutral» y puede requerir una relación de contraposición con el interrogado a fin de lograr su eficacia, de modo que deberían ser las partes quienes formulan las preguntas, lo que permitiría a quien juzga mantener «una distancia y una lucidez que nunca podría haber tenido si a la vez hubiera sido el protagonista». En segundo lugar, la «consciencia acerca de los amplios márgenes de falta 
En la misma línea, GuZMÁN (2006:147-57) recoge la distinción difundida entre los procesalistas italianos entre contradictorio para la formación de la prueba y contradictorio sobre la prueba ya producida, y considera al "principio de contradicción» como «una protección del imputado contra el ejercicio arbitrario del poder» y como un «método de búsqueda de la verdad» o un «modelo epistemológico que indudablemente coadyuva al conocimiento de la verdad».

2.2. De acuerdo con lo anterior, el derecho de interrogar a los testigos de cargo es uno eminentemente instrumental: la rectitud de la decisión es el objetivo final y, con ello, la evitación del riesgo de injusticia sustantiva. Si ese es el fin, estimo que una regla rígida de exclusión, inadmisión o prohibición de valoración ${ }^{19}$ en los casos de testigos no disponibles resulta un instrumento verdaderamente torpe para alcanzarlo, lo que es equivalente a señalar su irracionalidad epistemológica.

Para ir directo al punto, la defensa de una regla inflexible de inadmisión requiere asumir que no hay otro modo de saber si la información contenida en una declaración es o no confiable más que el interrogatorio o examen cruzado del testigo practicado por la defensa. Esto es incorrecto por varias razones. Para empezar, porque implicaría afirmar que si la defensa, aun teniendo oportunidad en el debate, decide no interrogar al testigo clave de la fiscalía, esto hará de su declaración una no confiable. Pero nadie descarta la información provista por un testigo solo porque la contraparte decida no contra-examinar ${ }^{20}$. Desde esta perspectiva, admitir la potencial debilidad

de credibilidad que, sin las adecuadas cautelas, presenta la prueba testimonial» pone al contraexamen en un lugar de preeminencia para «enfrentar el problema del error», por exhibir mayor aptitud que la técnica de la narración interrumpida para poner al descubierto falsedades, omisiones, interpretaciones alternativas, imprecisiones, etc., en la declaración de una testigo.

19 Uso indistintamente estas expresiones, en tanto la distinción ente casos de exclusión y de prohibición de valoración podría considerarse, a nuestros efectos, como una puramente semántica. El resultado sería siempre la no-valoración del medio de prueba por el juzgador, como explica GUARIGLIA (2005:1921), aunque refiriéndose a los casos de prueba ilícitamente obtenida. Gracias a la observación de una de las personas revisoras de este trabajo, aclaro, no obstante, que la discusión sobre la admisibilidad de un elemento de juicio precede a la de su valoración y, por tanto, no hay que confundir los problemas que se presentan en los distintos momentos de la actividad probatoria (Ferrer BeLtrán, 2007:41-49).

20 Esto no quiere decir, como a veces se afirma, que con esto quede demostrado que la confiabilidad de la evidencia no sea el único y ni siquiera el principal objetivo del derecho a la confrontación u otros derechos de intervención del acusado en el proceso (JaCKson y Summers, 20 i 2:362-6; Duff et. al, 2007:97-102). Al menos a primera vista, este tipo de señalamientos me parece más bien un juego de palabras. Creo que cuando se sostiene una mirada instrumental de tales derechos y se afirma que el objetivo último de la confrontación es la confiabilidad, nadie quiere decir con ello que el ejercicio efectivo de la cross-examination haga por sí mismo confiable toda declaración, ni que la ausencia de su práctica la torne necesariamente poco confiable o insegura. Lo que sí se quiere decir, en cambio, es que conviene darle al principal interesado (quien soportaría las consecuencias de una condena errónea) la posibilidad de detectar y poner de relieve errores, inconsistencias, dudas, etc. Se trata de una herramienta, entre otras varias dentro de los derechos procesales y probatorios de la defensa, idónea para alertar al decisor de la ausencia de confiabilidad de la información provista por un testigo. Que la defensa no la use, ciertamente no hace por esa sola razón confiable a la información, aunque pueda ser algo a tener en cuenta (la defensa no tiene líneas de contra-examen, el testimonio no perjudica su caso, etc.), al menos si asumimos que la defensa se ha preparado bien. De modo inverso, que la defensa no pueda usarla en 
de la evidencia, derivada de la pérdida de una herramienta útil para testearla, no es todavía un argumento suficiente para excluirla. Como se ha dicho de modo gráfico, excluir una prueba sólo con base en que no podría evaluársela del mismo modo que si hubiera sido expuesta a la cross-examination tiene tan poco sentido como la conducta de una persona hambrienta que rechaza un plato de comida solo porque no es tan nutritivo como podría ser (Ho, 2008:237) ${ }^{21}$. Cuando no hay más remedio que acudir a una declaración previa porque la testigo no está disponible, un fuerte argumento de sentido común nos indica que algo es mejor que nada, y que no hay necesidad de andar a ciegas sólo porque la luminosidad no es perfecta (PARK y SAKs, 2006:976-7).

En segundo término, aunque la imposibilidad de examinar a una testigo de cargo pueda poner al acusado en una posición desaventajada, es indudable que hay vías alternativas al interrogatorio o cross-examination que la defensa puede emplear para sembrar dudas sobre la historia contada por una testigo a la que no pudo interrogar. El ejercicio del contradictorio no acaba con la posibilidad de contraexaminar, pues incluye otras variadas facultades de intervención en el proceso para llamar la atención sobre las debilidades de un cierto elemento de prueba o, más ampliamente, de la hipótesis de la acusación (Ferrua, I992: 250-25I; GUZMÁn, 2006:I 47-72; Ferrer BeLtrán, 2007:86-90).

Además, la aclamada efectividad de la cross-examination, en aquellos lugares del mundo donde no sólo se la menciona sino también se la practica, en general depende, en opinión de sus defensores, de que el interrogador conozca la respuesta a la pregunta. Fórmulas como «no haga preguntas centrales cuya respuesta no conoce» $\mathrm{o}$ «no haga la pregunta de más» (aquella cuya respuesta puede ser una razonable aclaración de la testigo, por ejemplo) suelen ser lemas elementales del «buen contra-examinador» (CAROFiglio, 2007:29-30; 79-80). El conocimiento sobre las respuestas posibles de la testigo se obtiene a través de sus declaraciones previas, de declaraciones anteriores de otras personas, de inferencias que puedan extraerse del resto de la evidencia o de la tarea de investigación que pudiese haber emprendido la defensa. Si el ejercicio de esa técnica de interrogatorio es idóneo en un caso concreto para sembrar dudas sobre credibilidad del testigo, la precisión de la información que vierte, la existencia de lagunas en el relato o de interpretaciones distintas, etc., ha de ser, entonces, gracias al conocimiento en que se basan las preguntas. Esto quiere decir que hay vías

caso de testigos no disponibles, debe llamar la atención de un decisor responsable, pero esto no es en absoluto equivalente a afirmar que esa información no controlada de esa manera (a través del examen cruzado) sea per se insegura y deba ser descartada.

${ }^{21}$ Aunque hay que aclarar que esta y otras referencias críticas de Ho le sirven como punto de partida para buscar, desde una mirada o perspectiva interna (la del decisor), otros argumentos en defensa de la hearsay rule. Véase: Ho, 2008:232-283. AmaYa (2009:16-7 y 39-46), discute que los argumentos de Ho sirvan, en verdad, para fundar una regla de exclusión y explica por qué la idea de responsabilidad epistémica del juzgador como agente moral conduce, más que a privarlo de evidencia relevante (a veces crucial), a utilizar instrucciones que guíen a los jurados en sus deliberaciones, o a pedir que el juzgador explique las razones de su decisión. 
alternativas para presentar ante las personas llamadas a decidir la información que ha permitido diseñar las líneas de contrainterrogatorio cuyas respuestas se conocían de antemano ${ }^{22}$.

Por último, en la mayoría de los procesos la información resultante de la declaración previa se pone en relación con una serie de elementos de juicio. Así como existen casos donde la confiabilidad del relato puede ser puesta seriamente en duda, hay muchos otros donde se puede justificar racionalmente por qué la información es perfectamente confiable, con independencia de la falta de oportunidad de interrogar a uno o más testigos de cargo. Aunque volveré sobre esto último luego, basta con decir ahora que los casos más claros son aquellos donde la declaración previa del testigo no disponible está corroborada por varios elementos de prueba independientes entre sí, que no obstante requieren de esa declaración como elemento aglutinante que les da sentido.

Estos dos últimos puntos, cabe añadir, tienen cabida en la jurisprudencia actual de la Corte Europea dentro de lo que se ha denominado medidas de contrapeso o contrabalanceo, que remiten al análisis del modo en que el juzgador se ha aproximado a la valoración de la declaración previa del testigo ausente, de la disponibilidad y fuerza probatoria de otra evidencia de cargo y de la existencia e idoneidad de medidas procesales que hubieran sido adoptadas para compensar la falta de una oportunidad de interrogar a uno o más testigos en el juicio ${ }^{23}$.

22 Desde luego que puede ser más espectacular que el propio testigo, frente al auditorio expectante, se entregue a contradicciones o divagues, admita que ahora tiene dudas sobre lo que dijo o lo que vio, o lisa y llanamente confiese que ha mentido, como cuando Coronel Mayor Nathan R. Jessep (Jack Nicholson) sucumbe ante el contrainterrogatorio agresivo de Daniel Kaffee (Tom Cruise) en Cuestión de Honor (A Few Good Men), y acaba por admitir sin más que había ordenado el Código rojo ( $D i d$ you order de Code Red? - I did the job... - Did you order de Code Red? - You're goddamn right I did!»). Esa mayor eficacia persuasiva, no obstante, no desmiente que existan y puedan ser empleadas por la defensa vías alternativas a la cross-examination, como la posibilidad de ofrecer prueba de refutación, presentar evidencia en la que se basarían las líneas de contraexamen, o argumentar sobre la prueba y el nivel de suficiencia en el alegato de cierre. En la regulación de la CJA 2003, en Horncastle de la Corte británica y, con alguna reserva, en Al-Khawaja y Tahery de la Gran Sala de la Corte Europea, lo que está de fondo es, precisamente, la admisión de que hay variados instrumentos de los que la defensa puede echar mano para evitar el riesgo de injusticia sustantiva, si es que realmente tiene algo para decir.

He ampliado en buena medida estas ideas sobre la existencia de alternativas a la cross-examination gracias a las observaciones del profesor Aguilera García, que me hicieron notar esa posibilidad en busca de darle al texto mayor claridad.

23 Entre tales medidas, se considera si la aproximación del tribunal a la evidencia no testeada ha sido cuidadosa y demuestra que se ha tenido en cuenta la potencial debilidad de la declaración; la existencia de instrucciones en tal sentido al jurado; la motivación detallada del fallo sobre la confiabilidad de la declaración del testigo ausente; la existencia e importancia de otras pruebas que la defensa sí ha podido desafiar en el juicio y, especialmente, de prueba de corroboración; el modo en que ha sido registrada la declaración previa (por ejemplo, si lo ha sido en audio y video); si se ha dado al acusado y su defensa la oportunidad de exponer su propia versión de los hechos y de poner en duda la credibilidad del testigo ausente, señalando cualquier incoherencia o contradicción con las declaraciones de otros testigos; la posibilidad (cuando la identidad del testigo es conocida por la defensa) de que se adopten medidas de investigación destinadas a evaluar si el testigo puede tener ningún motivo para mentir o si 
2.3. Al menos en alguna medida lo brevemente expuesto explica que actualmente la rule against hearsay, en tanto regla de exclusión de prueba relevante, esté plagada de excepciones, o directamente retroceda y ceda lugar a regulaciones más flexibles (Ho, 2008:254-6). Detrás de todo esto está, como telón de fondo, la imperecedera discusión entre benthamianos y no-benthamianos acerca de las reglas probatorias intrínsecas, pero no hace falta ir tan lejos. Aquí alcanza con poner de relieve que la evolución de la hearsay rule en el common law, hoy mayormente codificada, ha sido relativamente coherente con los fundamentos seńalados arriba. Precisamente por eso se contempla como excepción a la regla de inadmisión, entre otras muchas, el caso de los testigos no disponibles, sea que esto se funde sólo en razones de necesidad, sea que se incorpore complementariamente una evaluación de confiabilidad ${ }^{24}$.

Por su parte, la tradición continental europea expresa, desde la reforma ilustrada y su simpatía hacia las instituciones inglesas, una preferencia por la producción de la prueba, sin intermediarios, ante el órgano decisor (el llamado principio de inmediación), pero nunca ha querido vedar la incorporación de declaraciones previas en casos donde hay buenos motivos para excepcionar el principio general ${ }^{25}$. Por otro lado, si bien el problema de la incorporación por lectura es equivalente, en buena medida, al de la admisibilidad de testimonial hearsay, no hay —en cambio- nada parecido a una regla general de inadmisión de non-testimonial hearsay, en el sentido de excluir la información que una testigo pueda brindar en juicio acerca de lo que dijo o implicó otra persona, para probar que esa aserción es verdadera. Sin embargo, creer que por ello los tribunales franceses, alemanes o espańoles valoran la prueba de "segunda mano" sin considerar el riesgo de error sustantivo es simplemente infundado. La idea de reglas intrínsecas de exclusión es ajena a la tradición de civil law, por numerosas razones, pero, desde luego, no lo es la cautela en el tratamiento de la evidencia posiblemente débil (DamašKa, I992:444-58; Delmas-Marty y Spencer et. al., 1995:618-9; Ho, 2008:255; JaCKSON y SumMERs, 2012:332).

pudo haberse equivocado, etc. Véase: TEDH, GS, Al-Khawaja and Tahery, \$147-165; Schatschaschwili, $\$ 107,114-6,125-31$ y $145-60$.

24 Véanse, a modo de ejemplo: FRE, Reglas 804 y 807; CJA 2003, Parte 11, Capítulo 2, Secciones $114,116,121$ y 124-126. En Al-Khawaja y Tahery (\$42-87), además de reseñar la CJA 2003 y la jurisprudencia inglesa, la Gran Sala de la Corte Europea presenta breves pero útiles referencias de derecho comparado sobre Escocia, Irlanda, Australia, Canadá, Hong Kong, Nueva Zelanda, Sudáfrica y Estados Unidos de América. Antes, en $R$. v Horncastle, la Suprema Corte británica había analizado comparativamente otras jurisdicciones de common law: [2009] UKSC 14, \$41 y Anexo I, preparado por Lord Mance.

25 Sirvan como ejemplo: StPO $\$ 250, \$ 251$; LECrim, arts. 448, 449, 657, 730, 777, 781.1, 784.2 y 797; CPP Colombia, arts. 15-16, 284, 378-9, 381, 391, 437-438, 441 [véase también: CSJ SP 606-2017, 25-ene-2017, Rad. 44950]; CPPN Argentina, arts. 200 y 391. Para buenas referencias a la legislación y jurisprudencia alemana, francesa, inglesa, española, holandesa, canadiense, entre otras, pueden consultarse: MAFFeI (2006); JaCKSON y Summers (20 I 2:332-4); Ho (2008:254-259); CHOo (2013); Vogler y Huber et. al. (2008: I 44-6, 243-4, 29 I, 3 I 8-9, 397, 409-I I, 43 5-8, 456-7); Youngs (i998:199-2ir); Delmas-Marty y Spencer et. al. (i995:6i6-20); Roxin (i979:393-403); Volk (I999:345-358); Pradel (1976:77I-779); Muerza Esparza (2016). 
2.4. Con estas bases, podemos analizar con algo más de detalle si reglas como la establecida por la Corte norteamericana en Crawford o la sole or decisive rule europea en su versión pre-Al-Khawaja son coherentes con los fundamentos del derecho de confrontación sintetizados arriba ${ }^{26}$.

De un lado, una regla-Crawford conduce a la inadmisión de todo testimonial hearsay si no hubo oportunidad previa de confrontación, sin importar el motivo por el cual el testigo no está disponible para el debate y sin importar cuan confiable resulte esa evidencia, considerada en sí misma, o a la luz del resto de los elementos de juicio que se ofrecen. Puede considerársela una regla rígida de inadmisión, de carácter atomista (JACKSON, 2018:8). La excepción es el caso de forfeiture by wrongdoing y probablemente el caso de dying declarations. En teoría, al menos, la distinción clave es testimonial/non-testimonial hearsay y los alcances de la excepción de pérdida del derecho, pero - aunque se la quiera desplazar de la escena - la cuestión de la confiabilidad emerge, disfrazada de ongoing emergency si es necesario, como supo notar (y lamentar) el propio redactor de Crawford, el juez Scalia, apenas unos años más tarde en Bryant (Epstein, 2009:44I-2; Madden, 2012:406-7, 414-7). ${ }^{27}$

${ }^{26}$ Con esto no asumo que, de hecho, la confiabilidad haya sido reconocida como el norte de la confrontación en Crawford, o en la jurisprudencia de la Corte Europea. En este último caso, de todos modos, ello podría afirmarse sin demasiado riesgo de error. Un análisis de racionalidad teleológica en Crawford es bastante más difícil, porque la Corte apela a los antecedentes históricos como clave de interpretación originalista y, de ese modo, no reconoce más excepciones que las que existían al tiempo de la puesta en vigor de la cláusula constitucional. Puede decirse, siguiendo la frase que PARK (2007:467) atribuye a Tillers (y que Redmayne, 2010:3 y 12, recoge), que para la Corte norteamericana el objetivo o propósito de la confrontación es la confrontación. Con otras palabras, en Crawford la pregunta acerca de qué excepciones a la confrontación reconocían efectivamente los Padres Fundadores reemplaza decididamente a la pregunta acerca de qué excepciones habrían reconocido (que es equivalente a indagar el porqué de las que entonces reconocían). Scalia y quienes lo siguieron cortaron los lazos con el porqué (telos) y, con ello, anularon toda posibilidad de interpretación finalista del derecho, sus alcances y excepciones.

27 En Bryant [562 U.S. 344 (2011)], el juez Scalia redactó una cáustica disidencia donde denunció y criticó este regreso velado a la doctrina de Ohio v. Roberts [448 U.S. 56 (1980)]. El caso era el del asesinato de Anthony Covington, del que había sido acusado Richard Bryant. La policía acudió al lugar a raíz de una llamada de emergencia que indicaba que alguien había recibido un disparo, y encontró a Covington en una gasolinera con una herida de bala en el abdomen. Se le preguntó de inmediato quién lo había herido y dónde había ocurrido el hecho. Covington respondió que Rick (Bryant) era el autor y que le había disparado en la casa de este último. La policía entonces se dirigió al domicilio de Bryant y allí encontró un orificio compatible con el paso de un proyectil de arma de fuego en la puerta trasera, una vaina servida en el suelo y sangre en el patio trasero. Covington falleció más tarde en el hospital. En el juicio, ante la imposibilidad de contar con el testimonio de la víctima, los oficiales de policía que habían recibido de Covington la información inicial testificaron sobre el contenido de esa declaración. Un tribunal de jurados condenó a Bryant por homicidio (second-degree murder). Planteado el caso constitucional como uno de infracción a la Sexta Enmienda, la Corte fue llamada a decidir si la evidencia - los dichos de Covington, introducidos a través de las declaraciones en juicio de los policías - había sido correctamente admitida. La opinión de la mayoría, redactada por la jueza Sotomayor, retoma la distinción trazada en Davis [547 U.S. 813 (2006)] entre testimonial y non-testimonial evidence, de acuerdo con la cual la información provista a la policía en respuesta a una situación de emergencia en curso (ongoing emergency) ingresa en este segundo grupo, mientras los interrogatorios cuyo fin principal es probar hechos pasados, potencialmente relevantes en un futuro proceso criminal, entran en el primero 
La sole or decisive rule de la Corte Europea, en cambio, no es atomista y ni siquiera es, estrictamente hablando, una regla de inadmisión o prohibición de valoración, aunque así se la interprete corrientemente. Incluso en su versión aparentemente inflexible, todo lo que la regla expresa es que una condena infringe el art. 6(3)(d) del Convenio Europeo si se apoya exclusiva o decisivamente en la declaración de un testigo que la defensa no ha tenido oportunidad de interrogar en algún momento del procedimiento. Se trata de una obligación de resultado (MAFFeI, 2006:71), que no necesariamente implica la obligación de una corte doméstica de inadmitir ese elemento de prueba. Además, es bueno notar que, aun en esta versión rígida, el funcionamiento práctico de la regla dependió siempre del alcance que se asignase a términos esquivos como decisivo, dirimente o determinante (Jackson y SumMers, 2OI 2:338-42; RedMAYNe, 2012:870).

TRECHSEL, uno de los comentaristas más serios de la jurisprudencia europea en materia de garantías aplicables al enjuiciamiento criminal, representa un inmejorable ejemplo de lo que buena parte de la doctrina, quizá dominante, sostiene acerca de la interpretación correcta o deseable de la sole or decisive rule. Dado que mi propósito en este apartado es explicar simplemente la irracionalidad epistemológica de una regla que inadmita sin más la declaración previa relevante de un testigo no disponible, utilizar la exposición de ese destacado autor como blanco de crítica está justificado ${ }^{28}$.

Para empezar, Trechsel advierte con razón que el derecho a examinar a los testigos de cargo es la única garantía del art. 6 del Convenio Europeo que se vincula directamente al modo en que se administra la evidencia. El aspecto más importante de la garantía no está expresado en el texto, pero es, a su ver, la consecuencia de su

(testimonial). La mayoría de la Corte norteamericana, luego, intenta justificar por qué ese caso sería uno de ongoing emergency, que caería dentro del conjunto de non-testimonial hearsay y, por ende, fuera del ámbito de cobertura de la Confrontation Clause, de acuerdo con la línea trazada a partir de Crawford. A ese fin, el argumento central es que los policías no sabían si el tirador seguía siendo una amenaza y que el caso involucraba un arma de fuego. En su voto disidente, Scalia indica que este caso «absurdamente fácil» debía resolverse de modo contrario: la declaración de la víctima, introducida por boca de los policías, era testimonial hearsay y, por ende, resultaba inadmisible debido a la falta de oportunidad de confrontación. En la crítica al criterio de la mayoría no le falta razón cuando afirma irónicamente, entre otras cosas, que, en esa supuesta emergencia en curso, al menos cinco policías distintos habían interrogado a Covington, que los interrogatorios ocurrieron al menos veinticinco minutos después de que aquel fuera herido y que ninguno de los oficiales le hizo la pregunta que lógicamente esperaríamos en una verdadera situación de emergencia (¿dónde está el tirador?). En este escenario, Scalia no oculta su frustración ante el hecho de que la Corte estuviese creando «una narrativa revisionista en la cual la confiabilidad sigue guiando la jurisprudencia en materia de confrontación, al menos en lo concerniente a emergencias y falsas emergencias», y critica el intento de la mayoría de «encajar su resucitado interés en la confiabilidad en el marco de la doctrina Crawford».

28 Debo aclarar que, aunque voy a examinar la posición que defiende desde ese punto de vista, el autor expone fundamentos no solo epistemológicos para el derecho reconocido en el art. 6(3)(d) del Convenio Europeo (Trechsel, 2005:292-3). Por otro lado, es bueno aclarar también que una crítica a la posición señalada encierra, asimismo, un ataque a la regla atomista norteamericana pues, desde la perspectiva de su racionalidad epistemológica, todo lo que se diga contra la sole or decisive rule vale, con mayor razón, para la regla-Crawford. 
incumplimiento. La pregunta central es qué sucede si la defensa no ha tenido una oportunidad de examinar al testigo que ha hecho una declaración previa. Estas son preguntas fundamentales en los procesos criminales domésticos y, según observa, se vinculan a la admisibilidad de la evidencia. A su vez, la decisión que se adopte sobre la admisión o inadmisión de una prueba tal probablemente determine el resultado del caso ${ }^{29}$. La declaración de que se ha violado ese derecho, indica, parece equivalente a un señalamiento del órgano internacional de que la persona ha sido erróneamente condenada.

TrechSel (2005:294) reconoce, no obstante, que la garantía tiene un carácter relativo. El mero hecho de que al acusado no se le provea la oportunidad de interrogar a un testigo o de que, a pesar del requerimiento de la defensa, el testigo no hubiera sido convocado, no puede por sí mismo llevar a la conclusión de que el proceso ha sido injusto, incluso cuando el acusado hubiera sido condenado. Una regla absoluta de esa clase constituiría un obstáculo desproporcionado para la administración de justicia y abriría la puerta de par en par a los abusos.

La naturaleza relativa de la garantía está estrechamente conectada con el tratamiento dispensado a la evidencia. Mientras que derechos como el de ser asistido por un abogado afectan la justicia del proceso con carácter general, independientemente de la cuestión sustantiva que hubiera estado bajo disputa, la oportunidad de examinar a los testigos adquiere relevancia a la luz de las específicas circunstancias de cada caso. En un juicio criminal, la pregunta es si la acusación ha presentado o no suficiente evidencia como para rebatir la presunción de inocencia, de modo que la condena esté justificada. Una declaración testimonial es un elemento de prueba; si hay muchos otros elementos de prueba, puede que aquella sea de mínima relevancia. En cambio, puede que haya muy poca evidencia adicional, en cuyo caso la declaración podría inclinar la balanza hacia la condena.

En síntesis, TRECHSEL (2005:295) explica que no es posible aplicar el art. 6(3) (d) sin tomar decisiones que al menos traen implícita una valoración acerca de si el peticionario debería o no haber sido absuelto. Para el autor, este es en esencia el problema que hace difícil la aplicación de la garantía y no cabe más que coincidir con esta apreciación.

${ }^{29}$ A mi ver, esto es solo parcialmente correcto. La exclusión, equivalente a asignarle a la declaración previa valor probatorio nulo, determinará probablemente el resultado del caso. No sucede lo mismo si la evidencia es admitida, pues esto no dice nada todavía acerca de la valoración y decisión. Puede que esa declaración previa luzca débil en el contexto probatorio específico de un caso y, por ello, se considere que la prueba reunida no alcanza para derrotar la presunción de inocencia. O puede que suceda lo contrario. Esto ocurre tanto en el sistema de jurados como en el de jueces profesionales, aunque en este último caso la expresión de razones permita un ejercicio posterior de impugnación, mientras que la inescrutabilidad del veredicto, en el primero, nos impida saber a ciencia cierta si los jurados han sido conscientes o no de las (posibles) debilidades de la información que la defensa no ha podido testear vía contra-examen. Esto último podría quizá encontrar remedio, sin embargo, en el empleo de instrucciones sobre las potenciales debilidades de la prueba hearsay y las razones por las que se requiere prudencia en la evaluación, a lo que debe añadirse el efecto de este tipo de instrucciones en la deliberación posterior de los jurados. 
Hasta aquí llegan, sin embargo, las coincidencias. TRECHSEL defiende una regla de exclusión de todo testimonio que la defensa no hubiera podido controlar en alguna etapa del procedimiento, cualquiera sea el motivo de la ausencia o la responsabilidad del Estado en la situación y sin entrar a considerar posibles medidas de contrapeso, bajo el argumento literal de que el del art. 6(3)(d) es una garantía minima que no se confunde con otras formas posibles de ejercicio de la defensa, ni con la advertencia de que las cortes domésticas deberían tratar a esta clase de evidencia con particular prudencia (2005: 294, 297, 308 y, especialmente, 313-15). Por tal razón, critica duramente la jurisprudencia de casos como Asch y Artner (2005:296, 314) y propone a las cortes domésticas, como método seguro para evitar una violación de esa cláusula, el de no referirse en el fallo a la declaración que no ha podido controlar la defensa (2005:298). Como se observa, entiende a la sole or decisive rule como una regla que lleva a preguntarse si es posible llegar a la misma decisión sobre la quaestio facti una vez que excluimos la declaración previa que la defensa no ha tenido oportunidad de controlar, una vez que removemos del mosaico probatorio cada pieza originada en esa declaración ${ }^{30}$.

Aquí llego a la cuestión medular. La interpretación que propone TRECHSEL de la sole or decisive rule - $\mathrm{y}$, con ello, del art. 6(3)(d) del Convenio- es una bastante difundida. Muchos autores analizan la cuestión como una de admisibilidad y pretenden identificar decisivo con relevante (SANCINETTI, 2002:869-70; GarCíA, 2002; O’Brian, 2011:114). Pero esta no es la única interpretación posible de la regla, ni es una que pueda fundarse en el objetivo último de asegurar la confiabilidad de la prueba y prevenir así condenas erróneas.

Como adelanté, la sole or decisive rule, incluso en su versión rígida, dice solamente que una condena no ha de basarse solo o decisivamente en una declaración previa que la defensa no ha podido controlar. No dice, en cambio, que esa declaración previa deba ser excluida o que valorarla en la decisión de un tribunal doméstico sea prohibido. La diferencia entre una cosa y otra puede no ser fácil de aprehender. Pero se aclara cuando indagamos bajo qué condiciones podemos afirmar que una condena se ha basado decisivamente en una declaración de esa clase. Solo si es decisiva cualquier pieza de evidencia que tenga aptitud, por mínima que sea, para inclinar la balanza hacia la condena, entonces tiene razón TRECHSEL en que las dos fórmulas son equivalentes. Pero no parece que ese haya sido el objetivo de la Corte Europea

30 Trechsel (2005:297) compara la evidencia en un caso criminal con las piezas de un mosaico. A menudo faltarán algunas piezas; de hecho, casi nunca será posible tener una imagen perfectamente completa (el mosaico en sí es una abstracción en tanto las piezas tienen un cierto tamaño). La evidencia es suficiente para destruir la presunción de inocencia cuando la imagen es inconfundible, lo que es equivalente a decir que no hay otra explicación razonable más que la culpabilidad del acusado. Luego, el análisis que propone para evaluar si una declaración ha tenido un peso decisivo en la condena es el siguiente: debemos remover cada pieza derivada de declaración que la defensa no ha podido controlar y preguntarnos si la figura es todavía inconfundible. Si lo es, entonces la condena no se ha basado decisivamente en esa declaración previa. 
al establecer la regla y, más allá de cierta vaguedad insuperable del concepto, desde luego no lo es desde Al-Khawaja y Tahery de la Gran Sala.

El ejercicio intelectual no es uno de supresión hipotética, sino uno bien distinto. La fuerza de los argumentos de la Corte británica en Horncastle obligó a la Corte Europea a precisar que, cuanto más corroborada está, la prueba es menos decisiva. Por ende, la aceptación de la sole or decisive rule no exige preguntarse si la condena se mantiene una vez que excluimos la declaración previa que la defensa no ha podido controlar vía interrogatorio. Cuando la Corte británica usa el ejemplo del hombre de barba que atropella y mata a un ciclista ${ }^{31}$ pone el énfasis en esto. Uso ese mismo caso con cierta libertad. Un sujeto observa el accidente de tránsito, tras el cual el conductor se fuga y el ciclista atropellado fallece. El testigo memoriza el número de patente del coche y, en su declaración ante la policía, indica también el color del automóvil y el hecho de que el conductor era un hombre de barba. La investigación de la policía conduce rápidamente al hallazgo de un coche con el número de patente $\mathrm{y}$ color indicados por el testigo, cuyo propietario es un hombre de barba. Este decide no responder preguntas sobre su paradero en el momento del accidente. Apenas unos días después, y antes de que tenga lugar el juicio, nuestro testigo fallece en otro accidente de tránsito.

Usemos ahora la metáfora del mosaico de Trechsel: ¿qué sucede si levantamos las piezas aportadas por la declaración a la policía del testigo ausente, si excluimos su testimonio? Todo lo que nos queda es una imagen bastante confusa, porque sin la declaración previa del testigo no es posible reconstruir la cadena de sucesos que condujo hasta ese automóvil y ese acusado, y no a cualquier otro. La conclusión, según este criterio, debería ser el dictado de una sentencia absolutoria. Pero salta a la vista que esta respuesta, derivada de la exclusión de una declaración altamente corroborada, es insensata. El mosaico de TrECHSEL es una ingeniosa metáfora, pero no sirve para resolver razonablemente casos como este ${ }^{32}$.

En cambio, hay distintas maneras aceptables de lidiar con un caso así. Una es estipular una definición de decisivo que no incluya en su campo semántico casos de declaraciones previas corroboradas o, más precisamente, que esté en relación inversamente proporcional al grado de corroboración, dado que se trata siempre de conceptos graduales. La otra es aceptar que se trata de un elemento de prueba

31 [2009] UKSC 14, $\$ 91$.

32 Un esquema probatorio similar es el que explica la sensata decisión de la Gran Sala en $\mathrm{Al}$ Khawaja. Según la Corte Europea, "[l] a confiabilidad de evidencia tenía apoyo en el hecho de que S.T. le había contado lo sucedido a dos amigos, B. F. y S. H., poco tiempo después de los acontecimientos, y que solo había diferencias mínimas entre su declaración previa a la policía y lo declarado en el juicio por esas dos personas de su confianza. Más importante aún, había notables similitudes entre la descripción del presunto abuso hecha por S.T. y el de otra víctima, V.U., sin que existiera ninguna evidencia de confabulación entre una y otra. En casos de abuso sexual cometidos por un médico contra una paciente durante una consulta privada, sería difícil concebir una prueba de corroboración más fuerte, especialmente cuando cada uno de los otros testigos fue llamado a declarar en el debate y su credibilidad pudo ser testeada mediante el contra-examen» $(\$ 156)$. 
central para el caso de la fiscalía - y, por lo tanto, decisivo - pero evitar una regla inflexible y aceptar que otras medidas de contrabalanceo, incluida la alta confiabilidad de la declaración no testeada vía contraexamen, pueden garantizar la justicia global del proceso y la seguridad de la condena. La Corte Europea empleó las dos vías al reinterpretar la regla a partir de Al-Khawaja $^{33}$.

2.5. La síntesis de lo anterior es la siguiente: una interpretación del derecho a la confrontación que tenga por corolario una regla-Crawford o incluso una regla como la sole or decisive rule en su versión pre-Al-Khawaja es indefendible desde el punto de vista del fundamento que, según asumimos al comenzar, justifica su existencia (la evitación del riesgo de injusticia sustantiva) ${ }^{34}$.

En casos de testigos no disponibles, una interpretación del derecho en cuestión que no pierda de vista esa finalidad instrumental desaconseja el empleo de una respuesta drástica y sobreinclusiva como las señaladas. Como hemos visto, excluir prueba relevante $-\mathrm{y}$, en ocasiones, de gran fuerza probatoria - no es ni el mejor ni el único instrumento para obrar con responsabilidad epistémica, ni es tampoco el único modo de compensar al acusado el déficit de confrontación ${ }^{35}$.

33 TEDH, GS, Al-Khawaja y Tahery, $\$ 131$ y 146-7.

34 Quizá los defensores de la tesis que critico podrían objetar todavía, con argumentos del utilitarismo de reglas, que, sin una regla rígida de inadmisión, los jueces tenderían a admitir demasiado fácilmente declaraciones previas que la defensa no hubiera podido controlar. La objeción no me parece convincente. Como ha notado Redmayne (2010:28-29), esto sería en todo caso un argumento en favor de una regla clara, pero no uno en favor de una regla-Crawford u otra similar. Si el argumento es uno más general en favor de cierto paternalismo epistemológico, derivado de la desconfianza hacia los encargados de tomar la decisión, creo que esa sola idea no alcanza para justificar la inflexibilidad de la regla de inadmisión y tiene serios problemas de base. Ese argumento, en efecto, es uno que no reconoce límites (Redmayne, 2012:877). Si nos tomamos en serio la idea de que toda evidencia potencialmente débil debe ser excluida del conocimiento del decisor para evitar el riesgo de condena errónea, quizá acabemos por excluir toda evidencia (RedmaYne, 2010:22). Incluso bajo la lógica de las reglas intrínsecas de exclusión, de la que no puedo ocuparme en detalle, solo habría razón para excluir prueba relevante si, por caso, hay evidencia empírica de que las personas llamadas a decidir, tendencialmente, le otorgan un valor excesivo o desmedido. Pero los estudios empíricos sobre hearsay no parecen apoyar esa tradicional sospecha dirigida centralmente a los jurados (PARK, 2003; SAKS y SPELLMAN, 2016:111-136 y 181-201).

Ha sido el profesor Bárcena Zubieta quien me advirtió de una posible objeción desde el utilitarismo de reglas, que intento contestar brevemente en esta nota.

${ }^{35} \mathrm{Si}$ no lo interpreté mal, el profesor Ferrer Beltrán me señaló que, aun siendo probablemente correctos mis puntos de partida, quizá la crítica que presento corra el riesgo de pecar de excesivamente moderada. El desarrollo de algunas de las ideas que expuse grosso modo podría llevarnos, más bien, a repensar completamente al menos algunos rasgos centrales de nuestros procesos criminales. Este es un punto demasiado amplio como para intentar contestarlo aquí. Entre quienes se han planteado interrogantes similares, ROBERTS y ZuCKERMAN (2004:212-289) encaran una evaluación profunda acerca del impacto de los hallazgos empíricos en el campo de la psicología experimental y de los avances tecnológicos en otras áreas, en institutos tan claves como la recepción oral, en vivo, concentrada, de los testimonios. Comparto, en sustancia, la conclusión de estos autores (2004:287-289): sin perder de vista la importancia de ciertas reformas, sobre todo en casos de testigos especialmente vulnerables, no veo todavía en el horizonte propuestas de modificación radical de la fisonomía de nuestros juicios. En el ínterin, creo que este trabajo conserva, aunque modesta, cierta utilidad. 


\section{CUANDO LA VERDAD NO ALCANZA: ¿ARGUMENTOS NO-INSTRUMENTALES COMO CLAVE DE INTERPRETACIÓN?}

\subsection{Presentación: dos preguntas para encarrilar el análisis}

La concepción anterior, instrumental-epistémica, asume que el principal objetivo del derecho de interrogar o hacer interrogar a los testigos de cargo es el de permitir al acusado controlar la confiabilidad de su declaración. Como se ha visto, esta es la comprensión del fundamento del derecho presupuesta en la jurisprudencia de la Corte británica, tanto como en la de la Corte Europea (RedmaYne, 20 Io:IO-I I; DE WILDE, 2013:157).

Sin embargo, hay quienes señalan que el derecho de interrogar o hacer interrogar a los testigos puede ser pensado - alternativa o concurrentemente- como un derecho no-instrumental, uno que por razones éticas se sostiene independientemente de su contribución o utilidad para asegurar la rectitud de la decisión sobre la quaestio facti. Esto podría conducirnos a repensar las críticas expuestas en el apartado anterior (VARELA, 2016a:213-16).

Si en la jurisprudencia falta una teorización explícita y desarrollada sobre los fundamentos y alcances del derecho analizado, no son pocos los autores que intentan justificar, sobre su vertiente no-epistémica, un derecho a la confrontación que tenga por corolario la adopción de un mecanismo de exclusión o prohibición de valoración rígido, equivalente a la regla-Crawford o la sole or decisive rule en su versión pre- $\mathrm{Al}$ Khawaja ${ }^{36}$.

Se sostiene, por ejemplo, que una persona que acusa a otra de un delito debería hacerlo en público, cara a cara y someterse a un escrutinio a través del interrogatorio, porque solo de este modo esa persona enfrentará el hecho de que sus acusaciones tienen un costo severo, uno que puede privar al acusado de su reputación, del contacto con su familia, de su libertad e incluso de su vida (O'Brian, 2005:500). De un modo parecido, aunque no idéntico, se apela a la idea de que, como sociedad, no aceptamos la cobarde y deshonrosa práctica de acusar y mantenerse a resguardo en las sombras. Como en el refrán popular: no vemos bien la conducta de tirar la piedra y esconder la mano. Quien acusa debe estar dispuesto a dar la cara y un derecho a la confrontación robusto garantiza esto (CLARK, 2003), un derecho a que a uno le digan las cosas en la cara.

Con una mirada puesta más en la dignidad del acusado que en las obligaciones morales de los acusadores, se sostiene — por otro lado- que el derecho de interrogar a los testigos de cargo es una manifestación del valor de la participación del acusado y, con ello, una expresión del derecho a ser tratado como una persona y no como

36 En efecto, como se adelantó en la Introducción, los autores que defienden posiciones como esta suelen hacer hincapié en el costado no-epistémico, lo que implica un reconocimiento, más o menos explícito, de que la discusión en el terreno de la racionalidad epistémica está perdida para ellos. Véase, por ejemplo, Friedman (ig98a y 2002); Nanzer (2008); Alcácer Guirao (2013). 
una cosa, como sujeto y no como mero objeto del proceso, a ser consultado y no simplemente a que se encarguen de uno (MASSARO, I988:904; SCALlEN, I992:626-7 y 64 I-3; Choo, i 996:37-42 y 201 3:246-7; O’Brian, 20 i i: i i 3; Alcácer Guirao, 2013:13).

O bien que el tristemente célebre juicio a Sir Walter Raleigh y otros penosos antecedentes históricos ${ }^{37}$ demuestran de modo paradigmático la posibilidad de abuso y manipulación estatal en un sistema sin derecho a la confrontación (BERGER, I 992; O'Brian, 2005; Redmayne, 2010:14-16).

Este conjunto algo heterogéneo de propuestas de fundamentación del derecho a la confrontación debe ser considerado seriamente. Si una regla inflexible de prohibición de uso, en caso de testigos no disponibles, no se puede defender desde el punto de vista de su racionalidad epistemológica, quizá una mirada no instrumental del derecho pueda justificarla. En todo caso, la capacidad de estas propuestas para dar solución a casos difíciles como los que analizamos no puede ser asumida a priori y depende de la respuesta a dos preguntas de distinto alcance.

Primero, una pregunta de alcance general y de difícil respuesta en el terreno de la filosofía política llama la atención sobre la posibilidad de defender fundamentos morales autónomos para las exigencias de participación del acusado en el proceso, razones de principio que vayan más allá de su justificación instrumental como procedimientos que contribuyen a la precisión de las decisiones de hecho y a la consiguiente corrección en la aplicación de la ley sustantiva (TRIBE, I978:504-4; DwORKIN, 1985:137-9). De modo más sintético y para usar la expresión de STEIN (2005:31): ¿tiene sentido la idea de free-standing evidencial rights?

Segundo, si aceptamos que hay razones no-epistémicas que justifican la existencia de derechos de intervención y trato en el proceso ${ }^{38}$, un segundo interrogante, de alcance más acotado, le sigue al anterior. Habría que preguntarse ahora si, sobre esas bases, el derecho a la confrontación es un derecho a interrogar o contra-examinar a los testigos disponibles y, más genéricamente, a exigir que la acusación sea responsable en la presentación de la mejor evidencia disponible ${ }^{39}$, o si es también un derecho a que la acusación se vea privada de utilizar en apoyo de su caso declaraciones previas de un testigo que ya no está disponible por motivos serios y atendibles.

Razones de orden epistemológico apoyan decididamente la primera tesis, y no la segunda. Ahora bien, esto no quiere decir que los fundamentos no-epistémicos, por

37 Véase Spotтswood (2018:570-8), para un repaso de los antecedentes históricos que pueden explicar la inclusión de la Confrontation Clause en la Sexta Enmienda de la Constitución norteamericana.

38 Como los derechos a conocer de qué se lo acusa a uno, a ser oído, a ofrecer prueba y a controlar la prueba de cargo, a presentar una explicación de lo que ha pasado y a conocer las razones de la decisión.

39 Precisamente en el principio de la mejor evidencia disponible (best evidence principle), al que se le han atribuido credenciales de principio unificador del derecho probatorio (NANCE, 1988), puede encontrarse la clave de interpretación de los alcances del derecho de confrontación. Razones de extensión, como adelanté, me impiden desarrollar el punto en este trabajo, pero pueden consultarse, como ejemplos en esa línea, las propuestas de Redmayne (2010:26-30) y SpotTswood (2018:588-611). 
mero culto de la simetría, conduzcan a la conclusión contraria. En cambio, el ejercicio intelectual consiste en considerar a qué soluciones nos llevaría, en casos como Al-Khawaja o Horncastle, poner el foco en tal o cual fundamento del derecho en cuestión. Esta última aclaración, superflua a primera vista, tiene algún sentido. Me parece que algunas veces se asume, equivocadamente, que una respuesta afirmativa a la primera pregunta es por sí misma un buen argumento en apoyo de una reglaCrawford u otra similar. En ciertos trabajos (NANZER, 2008:346-7 y 360-7; AlCÁCER Guirao, 2013:13; Díaz, 2017:95-7, 146-7 y 161-6) se presupone que la aceptación de fundamentos no (solo) instrumentales a la evitación del riesgo de error en la decisión para el derecho de examinar a los testigos conduce necesaria y naturalmente, sin otras consideraciones, a la conclusión de que interpretaciones como las de la Corte Europea en Al-Khawaja o Schatschaschwili o la Corte británica en Horncastle serían inaceptables. Esto es simplemente equivocado: la consideración de posibles fundamentos no-epistémicos puede enriquecer la discusión sobre los alcances del derecho y, con ello, aportar razones para tomar partido por alguna de las posiciones en pugna. Pero este es el punto de partida de posibles argumentaciones a favor de una regla rígida de exclusión o prohibición de uso, no el punto de llegada. Dejo esto para lo que sigue, con el fin de volver ahora a la primera pregunta.

\title{
3.2. La primera pregunta: pensar en un mundo de decisores infalibles
}

Suele emplearse un conocido pasaje de Tribe (Dworkin, i985:I37; Stein, 2005:3 I; Duff et.al., 2007:100) para reflexionar acerca de la respuesta correcta al primer interrogante. TRIBE (1978:503-504) distingue entre dos posibles fundamentos de principios para los derechos de participación que integran la noción de debido proceso o fair trial. Estos pueden entenderse de modo instrumental, justificados en tanto contribuyen a la precisión en la decisión y la correcta aplicación de la ley sustantiva, o bien entenderse de modo autónomo, como procedimientos intrínsecamente valiosos a los que las personas tienen derecho cuando el estado actúa de una manera que las individualiza, más allá del efecto instrumental en la rectitud del resultado. Esta última comprensión supone, como señala Tribe (1978:503-504), que:

\begin{abstract}
«tanto el derecho a ser oído como el derecho a ser informado de las causas son, analíticamente, diferentes del derecho a obtener una decisión distinta; estos derechos al intercambio expresan la idea elemental de que ser una persona, y no una cosa, equivale por lo menos a ser consultado sobre lo que se hace con uno [... Pues, cuando el estado actúa de una forma que individualiza a personas identificables (de un modo que probablemente parta de supuestos sobre personas específicas), despierta una inquietud especial porque se nos hable en forma personal sobre la decisión y no solo de que se encarguen de nosotros».
\end{abstract}

En el trabajo de Dworkin (1985:103-39) la pregunta por ese otro fundamento posible ingresa al final. Grosso modo, para Dworkin la adopción o rechazo de cierto tipo de procedimientos está en función de la especial consideración debida al riesgo de daño moral. El factor injusticia de una pena o daño moral es una noción objetiva que supone que alguien sufre un daño especial cuando recibe un tratamiento injusto, 
sin importar si lo sabe o si le importa, pero no lo sufre si no recibe un tratamiento injusto, aunque así lo crea y le importe. El factor injusticia no se confunde con el daño básico que sufre una persona como consecuencia de una pena, sea justa o injusta. Hay costo o daño moral no solo cuando deliberadamente se condena al que se sabe inocente, sino también cuando se condena a alguien por error, siguiendo procedimientos generales, en cierta medida riesgosos, dispuestos de antemano, aunque el factor injusticia sea mayor en el primer caso que en el segundo.

Los ciudadanos no tienen derecho a ser juzgados en los juicios más precisos posibles, cueste lo que cueste, ni a un determinado nivel de precisión (postulados extravagantes), pero tampoco es cierto que una persona imputada de un delito, o un individuo que acciona civilmente, no tenga derecho a ningún grado de precisión (postulados nihilistas). Dworkin da cuenta de dos tipos de derechos en sentido fuerte ${ }^{40}$ en materia de procedimientos penales: por un lado, los ciudadanos tienen derecho a que estos procedimientos asignen la importancia debida al riesgo de dańo moral ${ }^{41}$; complementariamente, tienen derecho a una ponderación coherente de la magnitud del daño moral ${ }^{42}$. El contenido de estos dos derechos, en suma, ofrece un punto medio entre los postulados nihilistas y los extravagantes.

La propuesta de Dworkin tiene por base, como se observa, una interpretación instrumental de los derechos procesales y probatorios, pues tiene como eje la noción de daño moral o factor injusticia y este, desde luego, está atado a la precisión en la decisión o resultado. No obstante, hacia el final de ese trabajo, el autor dice compartir la intuición de que en materia procesal hay más en juego que solo el daño moral asociado al riesgo de injusticia sustancial. El ejemplo que usa es aquel en el que se sanciona a alguien por un delito que estamos seguros que cometió, pero sin que se lo someta a juicio. La sensación de injusticia se vincula con la idea de que se debe oír a las personas antes de que la sociedad llegue a cierto tipo de conclusiones sobre ellas que redunden de algún modo en su descrédito moral. Es artificial, señala, suponer aquí que esto se asocia con el riesgo de que se condene a esa persona aun siendo inocente, porque el ejemplo presupone que estamos seguros de que el riesgo fue absolutamente nulo.

40 En «sentido fuerte» quiere decir que suponen un triunfo frente al cálculo de beneficios y pérdidas básicos que integra un cálculo utilitarista ordinario, lo cual deriva del hecho de que el daño moral o factor injusticia queda fuera de cualquier cálculo de esa índole, por más sofisticado que sea (1985:114 y 123).

${ }^{41}$ En los ejemplos que usa Dworkin, no le asigna la importancia debida al riesgo de daño moral una comunidad que decidiera casos penales lanzando una moneda al aire, o no permitiera que el acusado estuviera presente en su juicio, o impidiera que tuviese un abogado defensor o que presentase pruebas si así lo considerase conveniente (1985:123).

42 En casos difíciles el valor otorgado al riesgo de daño moral sería objeto de debate y puede no haber consenso al respecto entre personas razonables y sensatas. Este segundo derecho, señala, tiene especial importancia práctica en escenarios como ese, pues permite que un ciudadano alegue, aun en supuestos donde la respuesta correcta al problema del daño moral es muy discutida, que tiene derecho a disponer de procedimientos compatibles con el valor que la comunidad asigna al daño moral de acuerdo con lo plasmado en sus leyes (1985:123). 
Sin embargo, no es un dato irrelevante que el propio DwOrkin ${ }^{43}$ deje sin resolver la pregunta acerca de qué otro daño moral, distinto de ese riesgo de injusticia sustancial, puede ser encontrado en determinaciones de culpabilidad que no dan participación alguna al acusado. La cuestión, señala, es una demasiado vasta y en la que habría que seguir trabajando.

Volveré luego sobre esta poderosa intuición moral que Dworkin asume, pero deja sin justificación. Viene bien advertir, antes, que la respuesta a este primer interrogante en el que nos movemos no es uniforme. STEIN (2005:31-33) usa el mismo pasaje de la obra de Tribe como disparador de sus reflexiones, y lo conecta específicamente con las propuestas de otros académicos que, apoyándose en esa perspectiva, la extienden al campo de otras cuestiones de procedimiento y de derecho probatorio, como la que aquí nos interesa ${ }^{44}$. Aunque la idea de procedimientos y reglas probatorias con un valor ético intrínseco, no instrumental a la rectitud en la aplicación de la ley sustantiva — reconoce STEIN — es atractiva, hay razones de peso para ser escépticos.

En primer lugar, está el argumento que sintetiza en una frase: there can be no free-standing procedural rights because procedural rights cannot stand for free ${ }^{45}$. En situaciones de ineficiencia - los costos se expanden, pero no hay beneficios que los compensen - el legislador puede verse impelido a considerar un reemplazo para el procedimiento costoso. Hacerlo requeriría un análisis de costo-beneficio que compare el nuevo procedimiento con el existente. El análisis que STEIN describe es un cálculo utilitarista necesario a ese fin, pero una teoría que conciba a los derechos procedimentales de modo enteramente autónomo de los riegos de injusticia sustantiva, rechazaría cálculos utilitaristas de esa clase sobre bases deontológicas. Este rechazo, sin embargo, acarrea un problema infranqueable. Los recursos son escasos y no los hay en cantidad suficiente como para emplear el mejor procedimiento posible en

43 Dworkin (1985:138-139) no encuentra en la propuesta de TRIBE una categoría de daño moral relevante distinta de la falta de precisión. La idea de hablar con la gente en lugar de ocuparse de ella, o similares, no explica por qué el daño que causan las decisiones despersonalizadas no es simplemente un daño básico (que entraría en cualquier cálculo utilitarista bien hecho) y las aseveraciones sobre qué tipo de trato considera a la persona como persona y no como cosa son, como señala, conclusiones de argumentos, y no premisas.

44 Stein, en efecto, presenta una versión resumida de la clase de argumentos sostenidos en esa línea. Se sostiene, explica, que el derecho del acusado de contraexaminar a los testigos de cargo y la consiguiente exclusión de prueba hearsay debería ser percibida también como perteneciente a la familia de los derechos de intervención que son valiosos per se. La prueba hearsay no sería inadmisible por el riesgo de error que su admisión produciría. En cambio, lo sería porque someter a una persona a un juicio criminal sin darle una oportunidad de confrontar a los testigos adversos carece de justificación política. Una decisión fundada en relatos de testigos no testeados vía cross-examination bien podrían ser precisa. Su corrección no sería el asunto. El asunto, de adverso, sería preguntarse si una comunidad en la cual los juicios criminales son llevados a cabo sin amplia participación del acusado es atractiva en términos morales y políticos (STEIN, 1996:292-3; 2005:31-3). Luego me ocupo con más detalle de distintas variantes de este tipo de argumento.

45 Empleo la frase en su idioma original, para no suprimir el juego de palabras. La idea es la que se explica en el texto. 
cada disputa legal. Esto es algo que, como vimos, también Dworkin reconoce. En consecuencia, toda teoría de los derechos procesales debe concebir los criterios de distribución de los recursos de una manera o de otra.

La segunda razón se explica mediante una analogía de la litigación con un juego de suma cero (STEIN, 2005:32-3). Los procedimientos judiciales posponen la aplicación o ejecución de los derechos sustantivos en litigio. Esta dilación es, naturalmente, contraproducente para el titular del derecho de que se trate. Como en la máxima de Séneca, nada se parece tanto a la injusticia como la justicia tardía. Ahora bien, el derecho de una parte a ser oída debe ser entendido de tal modo que incluya el derecho a privar temporariamente de su derecho sustantivo a la contraparte. Esta privación provisional del derecho es inevitable. Sin embargo, difícilmente podría ser justificada si el derecho a ser oído fuese tomado como uno deontológico, no instrumental. Asúmase — dice STEIN — que el derecho a ser oído es independiente del riesgo de error en la decisión de hecho y completamente divorciado del derecho sustantivo subyacente. En este escenario, ¿por qué privilegiaríamos el derecho a ser oído de una parte sobre el interés de la otra de no verse privada temporariamente de su derecho sustantivo? Si una persona cuyos derechos son decididos sin darle oportunidad de ser oída es tratada como una cosa más que como una persona, ¿qué decir de la persona que se ve temporalmente privada de sus derechos debido a los derechos procedimentales provistos a su contendiente? ¿Se la estaría tratando como una cosa también?

Hay una última razón, lógica, que STEIN (2005:33) tiene en cuenta para ser escéptico acerca de la defensa de derechos procesales valiosos en sí mismos, esto es, con total independencia del riesgo de injusticia sustancial. El ejercicio que propone es similar al de la intuición moral de Dworkin, pero la respuesta es antitética. Supóngase un mundo donde el problema de la falibilidad epistémica no existe y en el cual los decisores son infalibles. ¿Habría lugar en ese mundo para derechos procesales y probatorios que fuesen considerados valiosos en sí mismos, más que instrumentalmente? Para STEIN la respuesta es negativa, a menos que estemos pensando en un simple ritual o en una concepción exótica de los derechos procesales como fuente de satisfacción psicológica o puramente catártica.

Como se ve, no todos comparten la intuición moral que Dworkin reconoce en propuestas como la de TRIBE, pero que, sin embargo, no logra fundar en una categoría de dańo moral relevante distinta de la injusticia asociada a la falta de precisión (Dworkin, 1985:137-9). Recordemos que, en el ejemplo de Dworkin de la persona condenada sin juicio, estamos «seguros» de que cometió el delito. Me parece que hay que preguntarse lo siguiente, sin embargo, en ese caso: jestamos todavía en nuestro mundo, un mundo donde falibilidad del razonamiento inductivo es quizá, y acaso paradójicamente, uno de los pilares del saber humano (GASCón AbelLán, 1999:1628)? ¿O estamos en un mundo contra-fáctico, el otro mundo posible de STEIN donde los juzgadores son perfectamente infalibles?

Quizá la fuerte intuición moral de Dworkin deja de parecernos tan poderosa una vez que aclaramos esos interrogantes. Puede que no sea tan «artificial», como señala, suponer en su ejemplo que la sensación de injusticia no se asocia al riesgo de que se 
condene a esa persona aun siendo inocente, pues «estamos seguros de que el riesgo fue absolutamente nulo» (1985:139). La trampa, tal vez, está en que Dworkin se pregunta por un ejemplar que no encontramos en este mundo y busca, no obstante, una repuesta de este mundo.

Un mundo donde el que decide es infalible no es este mundo, es el mundo contra-fáctico que propone STEIN. En este misterioso lugar, tal vez variarían radicalmente las ideas de TRIBE de hablar con la gente en lugar de encargarse de ella, o de tratar al prójimo como persona y no como cosa. Después de todo, como explica con maestría Dworkin (1985:138), las afirmaciones de qué trato considera a la persona como persona son, a lo sumo, conclusiones de argumentos, no premisas. No estoy seguro, pero quizá en ese otro mundo posible de STEIN a nadie se le ocurriría pensar en que una decisión tomada por un juzgador infalible sin oír previamente al sancionado signifique tratar a este como una cosa. Quizá, en cambio, en ese mundo de determinaciones de hecho infalibles sea visto como una burla, una broma de mal gusto, una falta de respeto, darle la palabra a alguien para que se defienda de una acusación cuyo mérito será decidido, invariablemente, sin ningún riesgo de error. ¿Para qué le haríamos perder el tiempo?

Si esto se comparte, habría que coincidir con STEIN en que el derecho a ser oído $y$, más ampliamente, todo el conjunto de derechos de participación en juicio, son derechos que, en última instancia, derivan de la necesidad de tomarse en serio la falibilidad epistémica, no de un puro virtuosismo moral independiente del riesgo de injusticia sustantiva ${ }^{46}$.

\subsection{La segunda pregunta: qué tipo de fundamentos y a dónde nos llevan (si es que nos llevan a algún lado)}

3.3.1. Lo anterior debería bastar para poner de relieve que hay buenas razones para ser escépticos acerca de garantías procesales de intervención valiosas per se, no instrumentales. Si argumentos como los de STEIN son correctos, entonces las propuestas que defienden un derecho a la confrontación absoluto sobre bases argumentativas no-epistémicas como las de TrIBE, resultan poco promisorias. Con todo, no

46 De ahí que, para resolver disputas como las que nos ocupa, contraponer argumentos epistemológicos y morales resulte poco fructífero. Además del de STEIN (2005), un atractivo análisis sobre esta relación es el de Ho (2008), que AmaYa (2009) comenta y amplía con nociones de responsabilidad epistémica y recursos de epistemología de la virtud. En particular, aunque Ho no analiza estrictamente el derecho de confrontar a los testigos de cargo (2008:268), cuando evalúa la hearsay rule en busca de los fundamentos que le sirven de sostén desde una perspectiva interna (la del juzgador como agente moral), aclara que el principio de justicia subyacente está intrínsecamente conectado al fundamento epistémico de la regla, sostiene que cualquier articulación del principio que omita esa conexión es poco promisoria y expone una convincente crítica al argumento que apela a la noción de justicia o equidad en un proceso adversarial — fairness argument - (2008: 264-8). Justicia y verdad no son, en lo que a este asunto concierne, objetivos separados y en competencia, sino metas concurrentes e integradas (2008:268). En la misma línea, MADDEN (2012:434-9 y 442-4). 
puede negarse que ese primero y más general de los interrogantes que nos planteamos es uno de difícil respuesta y hay un cierto margen para el disenso. Por tal razón, y para dar cabida a la segunda pregunta, podríamos aceptar a fines argumentativos que fundamentos que apelan al trato digno o la obligación moral de un testigo acusador de dar la cara, inter alia, son también razones que deben ser consultadas a la hora de dar forma y delimitar los alcances del señalado derecho.

En la introducción al problema presenté muy resumidamente algunos de los argumentos no-epistémicos usualmente sostenidos en apoyo de un derecho a la confrontación que se expresa en términos de una regla-Crawford o una igualmente rígida como la sole or decisive rule en su versión pre-Al-Khawaja. Ahora es la oportunidad de desarrollarlos y analizarlos con más detalle.

3.3.2. Empecemos con argumentos que extienden al campo de los derechos procesales y probatorios la tesis central de Tribe que discutíamos más arriba. Este tipo de argumentos es, quizá, el más recurrente entre aquellos que buscan una alternativa, o complemento, a los de tipo epistemológico.

Сноo (1996:37-42; 2013:246-7) apela al derecho de una persona a ser tratada con dignidad y a la confrontación como expresión del valor de la participación en el proceso penal, foro donde el acusado responde de los cargos en su contra. TRECHSEL (2005:293) también indica que el derecho a interrogar a los testigos y a presentar pruebas permite que el acusado sea un participante activo en el juicio, que no pueda ser caracterizado simplemente como el objetivo, pasivo, de la acusación, sino como un sujeto capaz de influir en el curso del proceso y en la dirección que este pueda tomar. Scallen (1992), Massaro (i988), Nanzer (2008), Alcácer Guirao (20 I3), VArela (2016a y b) y DíAz (2017), aunque hay naturalmente matices y diferencias entre sus posiciones, hacen propios argumentos de esa clase para dar forma al derecho en cuestión. Aunque hay espacio para la discusión, incluso la famosa sentencia de Scalia en Crawford de que "[p]rescindir de la confrontación porque el testimonio es obviamente confiable es semejante a prescindir del juicio por jurados porque el acusado es obviamente culpable» ${ }^{47}$, podría interpretarse en ese sentido.

El problema de esta clase de fundamentación es que puntos de partida tan generales y abstractos como la idea de trato digno o el empleo de fórmulas dicotómicas ejemplificativas (persona/cosa, sujeto/objeto y otras equivalentes), aunque pueda arrojar alguna luz sobre nuestras intuiciones morales en casos extremos de privación de derechos procesales o probatorios, difícilmente sean de ayuda cuando se trata de argumentar para casos difíciles cuya respuesta no es evidente. En otros términos, a menos que se asuma una definición estipulativa, no es para nada sencillo encontrar el umbral a partir del cual un determinado arreglo procedimental o probatorio ofende la dignidad del acusado, lo trata como cosa y no como persona ${ }^{48}$.

47541 U. S. 36 (2004), p. 62.

48 Tampoco suma afirmar que ese punto ya ha sido definido por la autoridad normativa (el legislador, digamos), al reconocerle al acusado un derecho de interrogar a los testigos, pues la discusión precisamente parte de esa base y busca desentrañar cuál es la mejor interpretación de los alcances de 
Este problema se observa fácilmente en un texto bastante citado como el de ALCÁCer Guirao (2013:13) que, de la idea de que al acusado debe permitírsele intervenir en el proceso y ser tratado «como sujeto y no meramente como objeto» deriva, sin otra argumentación, su conclusión de que la garantía no puede «ser sustituida por otras formas de asegurar la fiabilidad de los testimonios sin conllevar a la vez una considerable merma del derecho a un proceso equitativo». ¿Cómo discutir con una declamación como esta?

Nudas apelaciones a la dignidad del acusado, al ser tratado como sujeto y no como objeto, como persona y no como cosa, o a ser consultado en lugar de que se encarguen de uno, entre otras de pareja generalidad y abstracción ${ }^{49}$, simplemente no permiten escoger ante un menú de opciones que tenga por ejemplares a las interpretaciones de Crawford, Al-Khawaja o Horncastle. En efecto, solo a partir de una grosera caricaturización de posiciones como las de la Corte británica en Horncastle o de la Gran Sala de la Corte Europea en Al-Khawaja y Schatschaschwili podría equiparárselas con el caso en que se condena a un individuo sin juicio, o en el que se le impide tomar la palabra y expresar toda línea de defensa, o en el que se descarta sin motivos la prueba que ofrece.

Con esto se ve que la citada máxima de Scalia, a pesar de su aparente fuerza persuasiva, no nos sirve de mucho. No concibo cuál puede ser el argumento (moral o epistemológico) que permita equiparar una interpretación moderada del derecho a la confrontación con una condena sin juicio previo. La asimilación es engañosa y el argumento a mi ver definitorio lo ha dado RedmaYne (2010:21): la analogía con el juicio por jurados en Crawford soslaya que el derecho a ser juzgado por jurados no es uno que se pueda perder, a diferencia de lo que la propia Corte norteamericana predica respecto del derecho a la confrontación, para el cual reconoce la excepción de

ese derecho a partir de la consideración de sus fundamentos (así: [2009] EWCA Crim 964, \$26-8, 36 y 56). Dar un paso más y alegar, con base en la formulación de la cláusula que lo reconoce (la Sexta Enmienda de la Constitución norteamericana, por ejemplo), que no se han previsto excepciones [Friedman (I998a:I034-5; 2002:247); NANZer (2008:346-7)], además de cierto apego a un formalismo extremo difícil de justificar en el marco de la interpretación de disposiciones constitucionales, pondría a los sostenedores de esta tesis en el aprieto de tener que aceptar que no se puede echar mano de declaraciones previas incluso cuando el acusado asesina a los testigos de cargo para que no declaren en su contra. En tanto no se acepte también esto, la nuda referencia a la falta de excepciones en el texto es un muy débil argumento, que no merece mayor consideración. Para una buena contestación a Friedman, basada tanto en el texto de la Confrontation Clause como en los antecedentes históricos que explican su inclusión en la Constitución norteamericana, SpотTswood (2018:595-6).

49 En el mismo sentido, Madden (2012:433-44) advierte que el principal defecto de posiciones como la expuesta es que afirma una proposición que no se puede probar: ¿̇ómo podemos decir con autoridad que el procedimiento $\mathrm{X}$ es más respetuoso con la dignidad de un acusado que el procedimiento Y? La dignidad es un concepto tan abstracto que es difícil emplearlo de manera efectiva para defender una formulación concreta de una regla de evidencia. De modo que, en ausencia de alguna indignidad obvia derivada de la admisión de una declaración que no ha sido posible controlar vía contraexamen, la sugerencia de que la dignidad del acusado exige la exclusión de tal evidencia resulta poco convincente. 
forfeiture by wrongdoing ${ }^{50}$. Claro que podría afirmarse que la forfeiture es una sensata excepción a ese derecho, pero, en tal caso, ¿por qué razón no cabría admitir otras?

Veamos un ejemplo más (Massaro, 1988:904) entre las propuestas de interpretación basadas en la noción de trato digno:

"Las nociones de "juego limpio" y "trato digno" en las relaciones sociales y de negocios indican que la mayoría de las personas concede un valor intrínseco a los encuentros cara a cara [...] El ejército de Estados Unidos reconoce este valor intrínseco a través de su práctica de entregar en persona la noticia de la muerte de un hombre o mujer en servicio. Asimismo, en el mundo empresarial es 'indecente' despedir a un empleado con una carta, en lugar de hacerlo en un intercambio cara a cara. Usar una carta demuestra falta de respeto hacia la persona afectada, e implica que se la considera de menor estatus. Nuestra cultura, por lo tanto, considera que la entrega de malas noticias significativas a través de una carta, una llamada telefónica u otros dispositivos impersonales es la opción de la que echa mano un mensajero cobarde, o uno que carece de respeto por la igualdad, la humanidad y la dignidad del receptor».

El pasaje citado demuestra un mayor esfuerzo argumentativo y, como en Crawford, la analogía parece a primera vista cautivadora. Una mirada más cuidadosa, no obstante, permite notar que es al menos cuestionable: si el estado introduce como prueba la declaración previa de un testigo ausente, ¿iviola por esta razón la dignidad del acusado al tratarlo de un modo impersonal? El juicio en sí mismo sigue siendo un procedimiento cara a cara y el acusado oirá cualquier mala noticia —el veredicto de culpabilidad - a través de una entrega personalizada (REDMAYNe, 2010:19, en respuesta a este mismo extracto).

3.3.3. Otro tipo de argumentos no-epistémicos desplazan el foco del acusado hacia el testigo cuya declaración contiene una acusación. Aquí el punto central no es tanto que al acusado se lo trate como cosa y no como persona o argumentos similares, sino más bien que, en ciertas circunstancias, puede reputarse innoble y cobarde acusar en las sombras y luego rehuir la mirada de aquel que soportará las consecuencias de la acusación. El pasaje de Massaro transcripto más arriba puede interpretarse también en este otro sentido, lo mismo que algunos argumentos de O' Brian (2005:499-500) o FrIedMan (2002:247-51), y decididamente Clark (2003), quien emplea una metáfora bastante gráfica que atribuye a la idiosincrasia norteamericana: queremos - dice- pensar en nosotros mismos como personas que no apuñalarán a un hombre por la espalda, incluso - y aquí está la clave—si estamos totalmente convencidos de que merece ser apuñalado (2003:1263).

Propuestas como la de Clark sugieren una línea no-epistémica de argumentación, cuyas consecuencias frente a distintos grupos de casos habría que analizar cuidadosamente. Por un lado, de interpretarse el derecho a la confrontación bajo esta directriz, habría que admitir que el acusado carece del derecho de confrontar a un testigo, incluso importante para el caso de la fiscalía, si su declaración no es estricta-

50 Redmayne (2010:21) perspicazmente nota, asimismo, que en Giles v. California 554 U.S. 353 (2008) la mayoría reconoce este punto, pero lo usa en contra del argumento de la minoría en favor de una amplia forfeiture exception, en lugar de cuestionar la coherencia de su propia posición. 
mente acusatoria ${ }^{51}$. Por el otro, en la medida en que el principio rector es la inmoralidad del que acusa y evita dar la cara, difícilmente una teorización como la descripta justificaría la exclusión de la declaración hecha a la policía en Al-Khawaja — donde la víctima había fallecido- o en otros casos donde la inhabilidad para declarar en juicio obedezca a factores que no evidencien esa clase de cobardía o inmoralidad (Redmayne, 2010:16-18).

3.3.4. Por último, es útil identificar ciertos argumentos parecidos a los anteriores, algunos de los cuales se presentan a sí mismos como no-instrumentales, pero que, en un análisis más profundo, revelan una preocupación asociada a los riesgos de injusticia sustantiva y quedan absorbidos, en esa medida, dentro de los argumentos instrumentales-epistémicos.

En esta amplia categoría podemos ubicar a líneas argumentales como las que ponen el énfasis en la posibilidad de abuso, sugestión y manipulación de los interrogatorios policiales (BERGER, I992; O’ Brian, 2005), que REDMAYNe (2010:14-16) asocia con el «liberalismo del temor»; las que encuentran en el enfrentamiento público una oportunidad valiosa para que el testigo enfrente el peso que sus acusaciones cargan sobre la espalda de un congénere y se someta bajo estas condiciones al escrutinio del interrogatorio; o las más generales que apelan al temor del testigo mendaz a la vergüenza y escarnio público.

En el caso de las últimas dos líneas argumentales, la preocupación por la calidad epistémica de la información es fácil de detectar. Basta con poner de relieve que una de las más obvias razones para explicar por qué resultaría valioso que los testigos de cargo aprecien crudamente los costos que sus declaraciones acarrean al acusado es que esto los haría pensar dos veces antes de mentir o de hacer afirmaciones con ligereza. La habilidad del acusado y su defensa, a su vez, podrían ayudar a exponer mentiras y errores (REDMAYNE, 2010:14).

Lo mismo puede decirse de la primera línea de argumentos, vinculada con la necesidad de controlar el riesgo de manipulación policial, que llama la atención sobre la importancia del modo en que se registran los interrogatorios más tempranos, usualmente a cargo de la policía, y su posible incidencia en las declaraciones que tienen lugar en juicio (usualmente celebrado bastante tiempo después) a través del recurso a refrescar la memoria con base en los registros escritos ${ }^{52}$.

51 El propio CLARK pone el ejemplo del empleado de una empresa de mensajería que registra regularmente el tipo y número asignado a los paquetes que entrega en distintos domicilios, incluido el del acusado. Aunque la pregunta acerca de si este empleado entregó un paquete en particular al acusado devenga en un aspecto importante del caso de la fiscalía, no podría invocarse un derecho a confrontarlo. Véase, no obstante, Redmayne (2010:17-8), que se pregunta si no sería acaso innoble de parte del empleado evitar comparecer al juicio una vez que sabe que la suerte del acusado depende de la precisión de sus anotaciones.

52 Se trata de razones que deberían considerarse, usando la clasificación de Ho (2008:51-84), desde la perspectiva externa del ingeniero o diseńador del sistema, en busca de soluciones prácticas que desalienten o prevengan técnicas o conductas que deliberada o imprudentemente degraden la calidad de la evidencia, tanto como desde la perspectiva interna, la del llamado a decidir, entendido como 
En lo que respecta a la idea de desconfianza asociada a la memoria histórica de abusos del estado (la apelación al tristemente célebre juicio contra Sir Walter Raleigh), por último, esta ciertamente juega un papel en la comprensión del derecho a la confrontación, pues explicaría una interpretación del derecho donde se le exija a la fiscalía que presente la mejor evidencia disponible y, con ello, vedaría la posibilidad de incorporar por lectura la declaración de un testigo que sí está disponible. Esta interpretación responde suficientemente a la preocupación inherente al surgimiento de la garantía, al menos en buena parte de los casos y salvo que uno sea paranoico hasta el punto de creer, digamos, que el Estado orquestó el suicidio de la víctima en Al-Khawaja (Redmayne, 2012:877).

\section{PALABRAS DE CIERRE}

Si pasamos en limpio lo expuesto, podemos rescatar las siguientes conclusiones.

En primer lugar, el derecho de confrontación puede ser entendido como uno de tipo instrumental, asociado al riesgo de injusticia sustantiva, como una de las herramientas procesales que se ponen al servicio del acusado para permitirle testear y poner en duda la confiabilidad de la información provista por un testigo. Desde esta perspectiva, una interpretación del derecho que tenga por corolario una regla rígida de exclusión o prohibición de valoración de declaraciones previas de testigos no disponibles no está justificada, puesto que - en defecto de una prueba mejorexcluir evidencia relevante y, en ocasiones, de gran valor probatorio, no es la única ni la mejor manera de evitar el riesgo de error en la decisión de la quaestio facti.

En segundo término, las miradas alternativas, no-instrumentales, del derecho a la confrontación, que algunos autores invocan como un mantra para apoyar una reglaCrawford o criticar la flexibilización de la sole or decisive rule a partir de Al-Khawaja y Tahery de la Gran Sala de la Corte Europea, son verdaderamente estériles.

Por un lado, la idea de derechos procesales y probatorios valiosos en sí mismos, no-instrumentales, es difícil de justificar en alguna categoría moral distinta del riesgo de injusticia sustantiva y presenta, además, objeciones difíciles de superar.

Por el otro, admitiendo a fines argumentativos la relevancia de razones que basan los derechos de participación del acusado en nociones de trato digno y otras equiva-

agente moral. A este último respecto la idea de responsabilidad epistémica entraña un llamado a evaluar con suma prudencia la derrotabilidad de las inferencias derivadas de una declaración que no ha podido ser testeada (Ho, 2008:237-83; AмAYa, 2009:31-47). Volviendo al riesgo de sugestión en los interrogatorios policiales, REDMAYNe (2010:15-6) considera, en una opinión que comparto, que una medida como la grabación de los interrogatorios policiales puede ser una forma bastante más efectiva de controlar las técnicas policiales de manipulación y garantizar la calidad de la información, que la adopción de un derecho a la confrontación absoluto. A diferencia de un registro escrito y mediatizado, la grabación permitiría conocer lo que sucedió en los momentos más cercanos al hecho -el contenido de las preguntas, lo expresado exactamente en las respuestas-, con independencia de si el testigo está o no disponible para el juicio. 
lentes, hemos visto que estos se mueven en un nivel de generalidad y abstracción tal que no pueden ayudarnos a optar entre las alternativas que se encuentran en discusión para la definición de los alcances del derecho a interrogar a los testigos de cargo. Otras líneas argumentales enfocadas en los deberes morales de los testigos, restringen el alcance de la garantía a cierto tipo de declaraciones, al tiempo que resultan inidóneas para justificar una exclusión o prohibición de valoración de la declaración previa en casos donde el testigo no rehúye a dar la cara, sino que la ausencia responde a otros factores. Así, difícilmente sean de utilidad para defender una regla-Crawford o similar de manera indiscriminada. Por fin, otros variados argumentos que, en ocasiones, se presentan como no-epistémicos son, sin embargo, reflejos de las mismas preocupaciones por la rectitud de la decisión, cuya incidencia analizamos en primer lugar.

Queda pendiente para otra oportunidad el desarrollo de una propuesta de interpretación que apenas pude presentar rudimentariamente. De acuerdo con esta, el derecho analizado es uno a interrogar o contra-examinar a los testigos razonablemente disponibles y contiene la facultad específica de exigir que la acusación sea responsable en la presentación de la mejor evidencia disponible. En cambio, no abarca un derecho específico de exigir que la acusación se vea privada de utilizar en apoyo de su caso declaraciones previas de un testigo que ya no está disponible por motivos serios y atendibles.

La defensa de tal propuesta exigiría clarificar, entre otras cuestiones, en qué sentido se emplea en este contexto la noción de «mejor evidencia disponible»y, especialmente, considerar la espinosa cuestión de cómo deberían resolverse aquellos casos donde la imposibilidad de contar con el testigo en el juicio resultaba previsible para el órgano estatal encargado de llevar adelante la investigación previa.

\section{BIBLIOGRAFÍA}

Alcácer Guirao, R., 2013: «La devaluación del derecho a la contradicción en la jurisprudencia del TEDH», en InDret: Revista para el Análisis del Derecho, (4): 1-15.

Allen, R.J., 2009: «From the Enlightenment to Crawford to Holmes», en Seton Hall Law Rev, 39 (1): 1-16.

Amar, A. R., 1996: «Foreword: Sixth Amendment First Principles», en Georgetown Law Journal, 84: 641-712.

Aмaya, A., 2009: «The Ethics of Trial Deliberation: Moral Agency in Legal Fact-Finding», en International Commentary on Evidence, 7 (2): 1-47.

Anderson, T., Schum, D. y Twining W., 1991: Analysis of Evidence, 2a ed., New York: Cambridge University Press, 2005.

ANDRÉs IbÁNEZ, P., 2003: «Sobre el valor de la inmediación (Una aproximación crítica)», en Jueces para la Democracia, 46: 57-66.

- 2009: Prueba y convicción judicial en el proceso penal, Buenos Aires: Hammurabi.

Bayón Mohino, J. C., 2008: «Epistemología, moral y prueba de los hechos: hacia un enfoque no benthamiano", en Analisi e diritto, 2008:15-34.

Berger, M.A., 1992: «The Deconstitutionalization of the Confrontation Clause: A Proposal for a Prosecutorial Restraint Model», en Minnesota Law Rev, 76: 557- 600.

Carofiglio, G., 2007: L’arte del dubbio, Palermo: Sellerio Editore. Citado por la traducción castellana de Juanatey, L.: El arte de la duda, Madrid: Marcial Pons, 2010. 
CARral, D., 20 i i: El derecho a confrontar los testigos de cargo, Santa Fe: Rubinzal-Culzoni.

CARrió, A. D., 2007: «El derecho a confrontación de testigos de cargo. Garantía constitucional y un llamado a la realidad», en Revista de Derecho Penal y Procesal Penal, 2007-6:1092-.

Сноо, A. L. T., I996: Hearsay and confrontation in criminal trials, Oxford: Clarendon Press.

- 2005: Evidence, 4a ed., New York: Oxford University Press, 2015.

- 2013: "Criminal Hearsay in England and Wales: Pragmatism, Comparativism, and Human Rights», en Canadian Criminal Law Review, 17: 227-252.

Clark, S.J., 2003: "An Accuser-Obligation Approach to the Confrontation Clause», Nebraska Law Review, 81 (3):1258- 1286.

Contreras Rojas, C., 2015: La valoración de la prueba de interrogatorio, Madrid: Marcial Pons.

DамаšKA, M. R., 1992: «Of Hearsay and Its Analogues», en Minnesota Law Review, 76: 425-458.

- 1997: Evidence Law Adrift, New Haven-Londres: Yale University Press. Citado por la traducción castellana de Picó i Junoy, J.: El derecho probatorio a la deriva, Buenos Aires: Marcial Pons, 2015.

Delmas-Marty, M. y Spencer, J.R. et. al., I995: Procédures pénales d'Europe, París: Presses Universitaires de France. Citado por la edición en inglés (2002): European Criminal Procedures, reimp. de la ed. en rústica, Cambridge: Cambridge University Press, 2006.

Dennis, I., 2010: «The Right to Confront Witnesses: Meanings, Myths and Human Rights», en Criminal Law Review (4):255-274.

DíAz, E. M., 2017: Sobre la verdad y la protección de la inocencia en el proceso penal, Buenos Aires: AdHoc.

Diaz Cantón, F., 2009: «Declaraciones de menores de edad víctimas de abuso en Cámara Gesell y el derecho del imputado a la confrontación con los testigos de cargo", en Revista de derecho procesal penal, (1): 227-255.

Duff, A. et. al, 2007: The Trial on Trial: Volume 3. Towards a Normative Theory of the Criminal Trial, Oxford-Portland: Hart Publishing.

Dworkin, R., 1985: A Matter of Principle, Cambridge: Harvard University Press. Citado por la traducción castellana de Boschiroli, V. d. l. A.: Una cuestión de principios, Buenos Aires: Siglo Veintiuno Editores, 2012.

Epstein, J., 2009: «Cross-Examination: Seemingly Ubiquitous, Purportedly Omnipotent, and "At Risk"”, en Widener Law Review, 14 (2): 427-451.

Ferrajoli, L., 1989: Diritto e ragione. Teoria del garantismo penale, Roma: Laterza. Citado por la traducción castellana de Andrés IbáŃEz, P. et al.: Derecho y Razón. Teoría del garantismo penal, 9a ed., Madrid: Trotta, 2009.

Ferrer Beltrán, J., 2007: La valoración racional de la prueba, Buenos Aires: Marcial Pons.

- 2010: «Una concepción minimalista y garantista de la presunción de inocencia», en Revista de la Maestría en Derecho Procesal, Pontificia Universidad Católica del Perú, 4 (1): 1-26.

Ferrua, P., 1992: «Contraddittorio e verità nel processo penale», en Studi sul processo penale, Torino: Giappichelli, 2: 47 ss.. Citado por la traducción castellana de Filippi A. y López Puleio M.F., "Contradictorio y verdad en el proceso penal», en Gianformaggio, L. (ed.); Eiroa P.D. y Guzmán N. (coord.), Las razones del garantismo. Discutiendo con Luigi Ferrajoli, Bogotá: Temis, 2008, 218257.

Friedman, R.D., 1998a: «Confrontation: The Search for Basic Principles», en Georgetown Law Journal, 86 (4): 1011-1043.

— 1998b: «Thoughts From Across the Water on Hearsay and Confrontation», en Criminal Law Review, 697-709.

- 2002: "The Conundrum of Children, Confrontation, and Hearsay», en Law and Contemporary Problems, 65: 243-255.

- 2004: “Face to Face": Rediscovering the Right to Confront Prosecution Witnesses», en The International Journal of Evidence \& Proof, 8: 1-30.

- 2005: "Grappling with the Meaning of "Testimonial”", en Brooklyn Law Review, 71 (1): 241-280.

GARCíA, L.M., 2002: «El derecho a interrogar a los testigos de cargo en caso de abuso sexual sobre nińos. Nota al caso "P.S. v. Alemania"”, en Revista La Ley, 2002-F:15- 
Gascón Abellán, M., 1999: Los hechos en el derecho. Bases argumentales de la prueba, 3a ed., Madrid: Marcial Pons, 2010.

González Lagier, D., 2005: Quaestio facti. Ensayos sobre prueba, causalidad y acción, Lima: PalestraTemis.

Graham, M. H., 1988: «The Confrontation Clause, The Hearsay Rule, and Child Sexual Abuse Prosecutions: The State of the Relationship», en Minnesota Law Review, 72: 523-601.

Guariglia, F., 2005: Concepto, fin y alcance de las prohibiciones de valoración probatoria en el procedimiento penal. Una propuesta de fundamentación, Buenos Aires: Del Puerto.

Guzmán, N., 2006: La verdad en el proceso penal. Una contribución a la epistemología jurídica, 2a ed., Buenos Aires: Del puerto, 2011.

Ho, H. L., 2008: A Philosophy of Evidence Law: Justice in the Search for Truth, Oxford: Oxford University Press.

JaCKsON, J.D., 2018: «Common Law Evidence and the Common Law of Human Rights: Towards a Harmonic Convergence?», borrador de su ponencia presentada en el Congreso Mundial sobre Razonamiento Probatorio, Girona, 6-8 de junio de 2018.

- y Summers, S.J., 2012: The internationalisation of Criminal Evidence. Beyond the Common Law and Civil Law Traditions, New York: Cambridge University Press.

Jauchen, E. M., 2010: «Derecho del imputado y su defensor a interrogar testigos y peritos de cargo y descargo", en Revista de derecho procesal penal, 1: 101-113.

Langbein, J. H., 1978: «The Criminal Trial Before Lawyers», en University of Chicago Law Review, 45 (2): 263-316.

- 1996: «The Historical Foundations of the Law of Evidence: A View from the Ryder Sources», en Columbia Law Review, 96: 1168-1202.

Laudan, L., 2006: Truth, Error, and Criminal Law: An Essay in Legal Epistemology, Cambridge University Press. Citado por la traducción castellana de VÁzquez, C. y Aguilera, E.: Verdad, error y proceso penal, Buenos Aires: Marcial Pons, 2013.

Lilly, G. C., 1984, «Notes: on the Confrontation Clause and Ohio v. Roberts», en Florida Law Review, $36,207-233$.

López Guerra, L., 2013: «El diálogo entre el Tribunal Europeo de Derechos Humanos y los tribunales españoles. Coincidencias y divergencias», en UNED. Teoría y Realidad Constitucional, 32: 139-151.

MadDen, M., 2012: «Anchoring the Law in a Bed of Principle: A Critique of, and Proposal to Improve, American and Canadian Confrontation and Hearsay Law», en Boston College International and Comparative Law Review, 35 (2): 395-448.

Mafrei, S., 2006: The European Right to Confrontation in Criminal Proceedings: Absent, Anonymous and Vulnerable Witnesses, Groningen: Europa Law Publishing.

MAIER, J. B. J., 1982: La ordenanza procesal penal alemana: su comentario y comparación con los sistemas de enjuiciamiento penal argentino, Buenos Aires: Depalma.

- 1989: Derecho procesal penal argentino, Buenos Aires: Hammurabi. Citado por la edición posterior titulada Derecho procesal penal: fundamentos, 2a ed., 4a reimp., Buenos Aires: Del Puerto, 2012.

Massaro, T.M., I988: «The Dignity Value of Face-to-Face Confrontations», en University of Florida Law Review, 40 (5):863-918.

Miranda Estrampes, M., 2018: «Prueba testifical y garantía de contradicción en la jurisprudencia del Tribunal Europeo de Derechos Humanos», en VÁzQuez, C. (coord.), Hechos y razonamiento probatorio, Buenos Aires: Editores del Sur, 299-366.

Mosteller, R. P., 1993: «Remaking Confrontation Clause and Hearsay Doctrine Under the Challenge of Child Sexual Abuse Prosecutions», en University of Illinois Law Review, 4: 691-807.

Muerza Esparza, J. J., 2016: «Sobre los límites a la prueba preconstituida en el proceso penal», en Revista General de Derecho Procesal, 39:1-22.

Nance, D.A., 1988, «The Best Evidence Principle», Iowa Law Review, 73: 227-297.

- 2004: «Rethinking Confrontation After Crawford», en International Commentary on Evidence, 2 (1).

NANZer, A., 2008: «La prueba derivada bajo el prisma del derecho a la confrontación», en PASTOR, D.R. (DIR.) y GuZMÁN, N. (coord.), Neopunitivismo y neoinquisición: un análisis de políticas y prácticas penales violatorias de los derechos fundamentales del imputado, Buenos Aires: Ad-Hoc. 
Nieva Fenoll, J., 2010: La valoración de la prueba, Madrid: Marcial Pons.

O'Brian, W.E., 2005: "The Right of Confrontation: US and European Perspectives», en The Law Quarterly Review, 121(3): 481-510.

— 2011: «Confrontation: the defiance of the English courts», en The International Journal of Evidence \& Proof, 15: 93-116.

Park, R. C., 2003: «Visions of Applying the Scientific Method to the Hearsay Rule», en Michigan State Law Review, (4): 1149-1174.

— y SAKs, M. J., 2006: «Evidence Scholarship Reconsidered: Results of the Interdisciplinary Turn», en Boston College Law Review, 47 (5): 949-1031.

— 2007: «Is Confrontation the Bottom Line? ", en Regent University Law Review, 19: 459-467.

Pettit, P., 1989: «Consequentialism and Respect for Persons», en Ethics, 100 (1): 116-126.

PIQUÉ, M.L., 2014: «El conflicto entre el derecho de interrogar a los testigos y el derecho de las víctimas de no ser revictimizadas. Algunas reflexiones a partir de "Gallo López"», en Jurisprudencia penal de la Corte Suprema de Justicia de la Nación, 16: 124-157.

Posner, R. A., 1999: «An Economic Approach to the Law of Evidence», en Stanford Law Review, 51: $1477-1546$.

Pradel, J., I976: Procédure pénale, 17a ed., Paris: Éditions Cujas, 2013.

Redmayne, M., 2010: "Confronting Confrontation», en Law, Society and Economy Working Papers, 10/2010: 1-30.

- 2012: "Hearsay and Human Rights: Al-Khawaja in the Grand Chamber», en The Modern Law Review,75 (5): 865-893.

Roberts, P. y Zuckerman, A., 2004: Criminal Evidence, Oxford: Oxford University Press.

Rothstein, P.F., 2015: «Unwrapping the Box the Supreme Court Justices Have Gotten Themselves into: Internal Confrontations over Confronting the Confrontation Clause», en Howard Law Journal, 58: 479- 520 .

Roxin, C., I979: Strafverfahrensrecht, 15a ed., Múnich: Beck. Citado por la traducción castellana de Córdoba, G.E. y PAstor, D. R. de la $25^{\mathrm{a}}$ ed. alemana de la obra iniciada y continuada hasta $8^{\mathrm{a}} \mathrm{ed}$. por Kenn, E. y hasta la $14^{\text {a }}$ ed. conjuntamente, Derecho procesal penal, Buenos Aires: Del Puerto, 2000

Saks, M. J. y Spellman, B.A., 2016: The Psychological Foundations of Evidence Law, New York: New York University Press.

Sancinetti, M.A., 2002: Análisis crítico del caso “Cabezas": el juicio, Buenos Aires: Ad-Hoc.

SCALlen, E.A., 1992: "Constitutional Dimensions of Hearsay Reform: Toward a Three-Dimensional Confrontation Clause», en Minnesota Law Review, 76: 623-654.

Schauer, F., 2009: Thinking Like a Lawyer: A New Introduction to Legal Reasoning, Cambridge: Harvard University Press. Citado por la traducción castellana de Schleider, T.J., Pensar como un abogado. Una nueva introducción al razonamiento jurídico, Madrid: Marcial Pons, 2013.

Seigel, M.L., 1992: «Rationalizing Hearsay: A Proposal for a Best Evidence Hearsay Rule», Boston University Law Review, 72 (5): 893-950.

Sklansky, D. A., 2009: «Hearsay's Last Hurrah», en The Supreme Court Review, (1): 1-82.

Spencer, J.R., 2008: Hearsay Evidence in Criminal Proceedings, Oxford: Hart Publishing.

- 2010: «Squaring up to Strasbourg: Horncastle in the Supreme Court», en Archbold Review, (1): 6-9.

Spottswood, M., 2018: «Truth, Lies, and the Confrontation Clause», en University of Colorado Law Review, 89: 565-611.

SteIn, A., 1996: «The Refoundation of Evidence Law», en Canadian Journal of Law and Jurisprudence, 9 (2): 279-342.

- 2005: Foundations of Evidence Law, Oxford-New York: Oxford University Press.

Summers, S. J., 2004: "The Right to Confrontation After Crawford v. Washington: A "Continental European" Perspective», en International Commentary on Evidence, 2 (1).

TARuffo, M., 1992: La prova dei fatti giuridici, Milán: Giuffré. Citado por la versión castellana de Manríquez, L. y Ferrer Beltrán, J., 2008: La prueba, Madrid: Marcial Pons. 
- 2009: La semplice verità: il giudice e la costruzione dei fatti, Bari: Laterza. Citado por la versión castellana de Accatino Scagliotti, D., Simplemente la verdad: el juez y la construcción de los hechos, Madrid: Marcial Pons, 2010.

Tомкоvicz, J. J., 20 I I: Constitucional Exclusion: The Rules, Rights and Remedies that Strike the Balance between Freedom and Order, New York: Oxford University Press.

Trechsel, S., 2005: Human Rights in Criminal Proceedings, Oxford: Oxford University Press.

Tribe, L. H., I978: American Constitucional Law, New York: Foundation Press.

Ubertis, G., 2015: Profili di epistemologia giudiziaria, Milán: Giuffrè. Citado por la traducción castellana de Andrés IbáNEz, P., Elementos de epistemología del proceso judicial, Madrid: Trotta, 2017.

VARELA, A., 2016a: «Juicio por jurados, el derecho probatorio y la regla de exclusión de la prueba "hearsay" en el derecho anglosajón", en El debido proceso penal, 2: 179-218.

— 2016b: «Apuntes sobre el derecho a confrontar a los testigos de cargo», en Jurisprudencia de Casación Penal, 1:155-195.

Vogler, R. y Huber, B. et. al., 2008: Criminal Procedure in Europe, Berlin: Duncker \& Humblot.

VolK, K., 1999: Grundkurs StPO, 7a ed., Munich: Beck, 2010. Citado por la traducción castellana de Nanzer, A. et al., Curso fundamental de Derecho Procesal Penal, Buenos Aires: Hammurabi, 2016.

Westen, P., 1978: «Confrontation and Compulsory Process: A Unified Theory of Evidence for Criminal Cases», en Harvard Law Review, 91 (3): 567-628.

- 1979: "The Future of Confrontation», en Michigan Law Review, 77 (5): 1185-1217.

White, P. J., 2003: «Rescuing the Confrontation Clause», en South Carolina Law Review, 54, 537-622.

WILDE, B. DE, 2013: «A fundamental review of the ECHR right to examine witnesses in criminal cases», en The International Journal of Evidence \& Proof, 17 (2): 157-182.

Youngs, R., I998: English, French and German Comparative Law, 3a ed., New York: Routledge, 2014. 